\title{
announcements/call for papers
}

\section{AMS 2001 Meetings}

11 th Conference on Interactions of the Sea and Atmosphere, 14-18 May 2001, San Diego, California

The 11th Conference on Interactions of the Sea and Atmosphere, sponsored by the American Meteorological Society and organized by the AMS Committee on the Interactions of the Sea and Atmosphere, 14-18 May 2001 in San Diego, California. This conference will be held in conjunction with the Sixth Conference on Polar Meteorology and Oceanography. The theme of both conferences is "air/sea/ice/land interactions."

A preliminary program, registration, hotel and general information have been posted on the AMS Web site (http://www.ametsoc.org/AMS). AMS recommends that attendees secure hotel reservations at the Catamaran Resort Hotel by 6 April 2001. For reservations, contact the Catamaran at (800) 288-0770.

The deadline for abstracts has passed. Papers on all aspects of air-sea interactions were encouraged, especially those that focus on midlatitudes to polar regions. Sessions on the results from recent field experiments, satellite remote sensing, and modeling studies are being considered. Joint sessions with the Sixth Conference on Polar Meteorology and Oceanography are likely to include 1) air-sea interaction in the presence of heterogeneous sea ice cover; 2 ) predictability of the polar climate system; and 3) influence of air-sea interaction on deep ocean convection. To encourage the interdisciplinary interaction among participants of the two conferences, an invited talk as an introduction overview is planned for each session. Participants with additional suggestions for special/joint sessions are encouraged to contact the program chairperson.

Registrants will receive a preprint volume at the conference. For further information contact the Program Chairperson, Xubin Zeng, Department of Atmospheric Sciences, P.O. Box 210081, Univ. of Arizona, Tucson, AZ 85721, USA (tel: 520-621-4782; fax: 520-621-6833; e-mail: xubin@atmo.arizona.edu). (7/00; r10/00; r1/01; r4/01)

\section{Sixth Conference on Polar Meteorology and Oceanography, 14-18 May 2001, San Diego, California}

The Sixth Conference on Polar Meteorology and Oceanography, sponsored by the American Meteorologi- cal Society and organized by the AMS Committee on Polar Meteorology and Oceanography, will be held 14-18 May 2001 in San Diego, California in conjunction with AMS 11th Conference on Interactions of the Sea and Atmosphere. The theme of the joint conference is "air/sea/ice/ land interactions."

A preliminary program, registration, hotel and general information has been posted on the AMS Web site (http://www.ametsoc.org/AMS). AMS recommends that attendees secure hotel reservations at the Catamaran Resort Hotel by 6 April 2001. For reservations, contact the Catamaran at (800) 288-0770.

The deadline for abstracts has passed. E-mailed acceptance letters were sent in mid January 2001. Papers were being solicited on all topics related to polar meteorology and oceanography, with particular emphases on surface fluxes of energy and moisture, cloud-radiation interactions, and model simulations of atmosphere-surface interactions. We welcome presentations of results from recent field programs (e.g., SHEBA and FIRE-ACE) and model intercomparison projects.

Registrants will receive a preprint volume at the conference. For further information please contact the Program Chairperson, Jennifer Francis, Institute of Marine and Coastal Sciences, Rutgers University, 71 Dudley Rd., New Brunswick, NJ 08901-8521 (tel: 732-708-1217; fax: 732-872-3088; e-mail: francis@imcs.rutgers.edu). (7/00; $\mathrm{r} 10 / 00 ; \mathrm{r} 1 / 01 ; \mathrm{r} 4 / 01)$

\section{SEAFLUX Intercomparison Workshop, 17-18 May 2001, San Diego, California}

A workshop entitled "SEAFLUX Intercomparison Workshop" will be held on 17-18 May 2001 at the Catamaran Resort Hotel in San Diego, CA. The need for highresolution, accurate surface turbulent fluxes (heat, water vapor, momentum) over the global ocean has been articulated by numerous groups within the global climate community. In August 1999, the GEWEX Radiation Panel and sponsored a workshop to review the analysis methods and data sets currently available and organize an intercomparison activity that includes in situ data, flux algorithms, satellitederived input parameters and fluxes, and NWP products, which has been named SEAFLUX. An overview of the SEAFLUX study is found at http://paos.colorado.edu/ $\sim$ curryja/ocean/. In response to this workshop, an inter-comparison project is being undertaken, towards developing rec- 
ommendations for improved methods of determining global, high-resolution ocean surface turbulent fluxes.

The SEAFLUX intercomparison project is being undertaken using an extensive web-based library of in situ data sets from research ships and buoysthat includes direct turbulent flux measurements, skin and bulk sea surface temperature, wave information, and surface air temperature, humidity, and vector winds. The following satellite data and NWP analyses have been colocated with the in situ measurements: SSM/I brightness temperatures, TRMM brightness temperatures, the Wentz SSM/I and TRMM retrieved products, AVHRR GAC data for cases with skin SST measurements, ISCCP and TOVS products, scatterometer winds, and the NCEP analyses of surface turbulent fluxes and the input variables. Also available on the SEAFLUX web site are the codes for 10 different bulk flux algorithms that are used either in satellite retrievals or GCMs. These codes are currently be evaluated using the in situ data that includes direct turbulent flux measurements.

Preliminary results from the intercomparison will be presented and discussed at the Intercomparison Workshop. Strategies and plans for future activities will be considered.

For further information, please contact Judy Curry, Univ. of Colorado, PAOS, Boulder, CO 80309 (tel: 303 492 5733; e-mail: curryja@cloud.colorado.edu) (4/01)

\section{3th Conference on Atmospheric and Oceanic Fluid Dynamics, 4-8 June 2001, Breckenridge, Colorado}

The 13th Conference on Atmospheric and Oceanic Fluid Dynamics, sponsored by the American Meteorological Society and organized by the AMS Committee on Atmospheric and Oceanic Fluid Dynamics, will be held 4 8 June 2001 at the Village at Breckenridge Resort, in Breckenridge, Colorado.

A preliminary program, registration, hotel and general information have been posted on the AMS Web site (http://www.ametsoc.org/AMS). AMS recommends that attendees secure hotel reservations at the Village at Breckenridge by 4 May 2001. For reservations, contact the Central Reservations at (877) 428-7829 or (970-547-5725).

The deadline for abstracts has passed. Papers were solicited in all subject areas of atmospheric and oceanic fluid dynamics. We especially encouraged the submission of papers emphasizing the dynamic interaction among different components of the ocean-atmosphere fluid system. Examples of such include (but are not limited to) the large scale dynamics of the coupled atmosphere-oceans system, dynamical interactions between the stratosphere and troposphere, gravity wave impacts upon the general circulation, communication between the deep waters and surface layers of the ocean, and interactions among eddies of different scales (in both space and time). Additional foci will include low frequency variability, the organization of storm tracks, intrinsic variability in the oceanic circulation, thermohaline flows, and potential vorticity dynamics. Invited speakers will include Drs. Clara Deser, Steven B. Feldstein, Kevin P. Hamilton, James C. McWilliams, John W. Nielsen-Gammon, Peter B. Rhines, Walter A. Robinson, and Darryn W. Waugh.

The meeting will also feature the Seventh Bernhard Haurwitz Memorial Lecture to be given by Dr. R. Alan Plumb. There will be a mix of oral and poster presentations. Poster submissions were especially encouraged, as dedicated poster sessions will receive increased stature compared to past meetings. To facilitate this goal, individual authors will be limited to one oral presentation each. Five prizes for the best student papers will be awarded at the conference.

Registrants will receive a preprint volume at the conference. For further information please contact the program chairpersons: Robert X. Black, School of Earth and Atmospheric Sciences, 21 Bobby Dodd Way, Georgia Inst. of Technology, Atlanta, GA 30332-0340 (tel: 404-894-1756; fax: 404-894-5638; e-mail: rob.black@eas.gatech.edu) or Sukyoung Lee, Department of Meteorology, 510 Walker Building, University Park, PA 16802 (tel: 814-863-1587; e-mail: sl@essc.psu.edu). (7/00; r9/00; r10/00; r1/01; $r 3 / 01 ; r 4 / 01)$

\section{Student Travel Grants}

Student Travel Grants are available for senior undergraduate and graduate students to attend AMS meetings held in the United States and Canada. The travel grants are available only to members, including student members, of the AMS.

AMS recognizes the considerable benefit that students can gain from attending conferences even if they are not presenting a paper there, and AMS wants to encourage interactions between students and other conference attendees. To this end, travel grants will be awarded to a student who is not presenting a paper at the conference.

Students who are presenting papers and potentially in need of travel support should inquire of the program chair whether any funds will be available for this purpose.

For more information and to complete an application form, please visit the AMS Web site at www.ametsoc.org/AMS. 
Workshop on Severe Weather Forecasting in the New Millennium for Broadcast Meteorologists, 26 June 2001, Minneapolis, Minnesota

A workshop entitled "Severe Weather Forecasting in the New Millennium for Broadcast Meteorologists" sponsored by the American Meteorological Society and organized by the AMS Board of Broadcast Meteorology will be held on Tuesday, 26 June 2001 at the Hilton Hotel in Minneapolis, Minnesota.

The conference program, travel, and registration information will be posted on the AMS Web site (http:// www.ametsoc.org/AMS) in February 2001. AMS recommends that attendees secure hotel reservations at the Hilton Hotel by 18 May 2001. For reservations, contact the Hilton at (612) 376-1000 or via the Web at www.hilton.com.

This one-day workshop will focus on current forecast procedures used in developing Convective Outlooks, Severe Weather Watches and Severe Weather Warnings. Topics will include models being used and developed for forecasting severe storms, operational techniques used in deriving the outlook, watch and warning products issued by the National Weather Service, and present new products and techniques. Meteorologists from NOAA Storm Prediction Center, National Weather Service Forecast Offices (NWSFO), and National Severe Storm Laboratory (NSSL) will share their research on the direction of severe weather forecasting. An actual case study will be included where participants will experience the warning decision process in deriving a severe weather forecast and issue watches and warning for an actual severe weather event.

For further information contact, the Short Course Organizer, Dan McCarthy, Storms Prediction Center, 1313 Halley Circle, Norman, OK 73069 (tel: 405579 0747; e-mail: mccarthy@spc.noaa.gov). (12/00)

\section{0th Conference on Broadcast Meteorology, 27- 30 June 2001, Minneapolis, Minnesota}

The 30th Conference on Broadcast Meteorology, sponsored by the American Meteorological Society and organized AMS Board on Broadcast Meteorology, will be held Wednesday 27 June-Saturday 30 June 2001 at the Hilton Hotel in Minneapolis, Minnesota. On Tuesday, 26 June 2001, AMS a workshop entitled, "Severe Weather Forecasting in the New Millennium for Broadcast Meteorologists (separate registration is required for this workshop-for details, refer to the announcement listed above) will be held.

AMS recommends that attendees secure hotel reservations at the Hilton Hotel by $\mathbf{1 8}$ May 2001. For reservations, contact the Hilton at (612) 376-1000 or via the Web at www.hilton.com. The conference program and registration information will be posted on the AMS Web site (http:// www.ametsoc.org/AMS) in February 2001.

The theme of the 30th conference will be, "Surviving the Changing World of Broadcast Meteorology." Since this is the 30th anniversary of the broadcast conference, we would like to look back at the beginning of broadcast meteorology and since it has changed so much over the years, how do we keep up with that change and how do we survive the future changes. Television and radio stations are bought and sold every day, how does that effect our jobs now and in the future.

This conference focuses on broadcasting with sessions pinpointing: 1) Changing Technology: How we present the weather; 2) Science vs. entertainment and management vs. audience expectation; 3) Holding on to that job with constant change . . . Station ownership and doing more with less; 4) Educating yourself and the viewer: What does the future hold for the broadcast meteorologist; and 5) We've come a long way ... Looking back at the beginning of broadcast meteorology.

The deadline for abstracts has passed. E-mailed acceptance letters will be sent by early February 2001.

For further information contact the Cindy Preszler, KSDK-TV, 1000 Market St., St. Louis, MO 63101 (tel: 314-444-5189; e-mail: WxPresz@AOL.COM;). The program is being organized by Cindy Preszler with assistance from Dave Miller, WFRV-TV, Green Bay, WI 54301 (tel: 920-437-5411 ext. 13241; fax: 920-437-4576) and AMS Board Chairperson, Mike McClellan, WMBD-TV, 3131 N. University, Peoria, IL 61604 tel: 309-686-8657). (7/00; $\mathrm{r} 9 / 00 ; \mathrm{r} 1 / 01 ; \mathrm{r} 2 / 01)$

\section{0th International Conference on Radar Meteo- rology, 19-24 July 2001, Munich, Germany}

The AMS 30th International Conference on Radar Meteorology, sponsored by the American Meteorological Society, and organized by the AMS Committee on Radar Meteorology, will be held 19-24 July 2001 in Munich, Germany. The theme of this conference is "Integrated approaches of using radar for understanding and predicting atmospheric and hydrologic processes."

A preliminary program, registration, hotel and travel information will be posted on the AMS Web site (http:// www.ametsoc.org/AMS). AMS recommends that attendees secure hotel reservations at the Forum Hotel Munich by 30 June 2001, although reservations may be made up until the day of the conference. For reservations, contact the Forum Hotel Munich at 011-49-89-4803-4444.

The theme of this conference is integrated approaches of using radar for understanding and predicting atmospheric and hydrologic processes.

The deadline for abstracts has passed. Papers were solicited that particularly emphasized: 1) integrated observations of radar with other ground-based, airborne, and/or spaceborne instrumentations; 2) assimilation and use of radar data in numerical weather prediction or hydrologic models; and 3) radar network-based diagnostic studies and climatological analyses. Contributions based on the Mesoscale Alpine Program (MAP), the Forecast Demonstra- 
tion Project Sydney 2000@ or COST-717, were especially encouraged. In addition, papers were solicited in the following areas: 4) radar systems and signal processing; 5) algorithms for radar echo type identification and retrievals, and their validation; 6) data management, quality control, and exchange; 7) quantitative precipitation estimation and validation; 8) Doppler and polarization techniques; and 9) others, as deemed appropriate.

The conference will foster interaction among the participants through formal presentations and informal discussion opportunities. Special sessions will be organized around the key theme for his conference, complemented by parallel and poster sessions. Although the authors may state their preference of oral or poster presentation, the program committee will make the final decision on format.

A preprint volume is being prepared and authors of invited and accepted papers will be asked to contribute to this volume. AMS will provide instructions to authors of accepted papers. Camera-ready manuscripts ( 3 pages), including photos and diagrams, must be submitted by 2 April 2001 to AMS Headquarters. Page charges will be assessed to defray printing costs. Registrants will receive a preprint volume at the conference.

To honor the memory of Spiros ("Speed") Geotis, who inspired many students in his career of more than 40 years, the Spiros G. Geotis Prize will be awarded for the best student paper. Students who wish to be considered for this prize should indicate that when submitting their abstract, and they must be lead author and presenter of the paper. Recent graduates who completed their degree requirements after the 29th Conference on Radar Meteorology (July 1999) are also eligible for the Geotis Prize. Papers must be based on work done by a student, or largely completed while a student, and will be judged on scientific content and presentation at the conference.

For further information contact: Peter Meischner, Institut fuer Physik der Atmosphaere, Deutsches Zentrum fuer Luft- und Raumfahrt (DLR), Oberpfaffenhofen, D82230 Wessling, Germany (tel: 49-8-153-28-2581; fax: 49-8-153-28-1841; e-mail: peter.meischner@dlr.de),or Matthias Steiner, Dept. of Civil and Environmental Engineering, Princeton Univ. , Princeton, NJ 0844 (tel: 609-2584614; fax: 609-258-2799; e-mail: msteiner@ princeton.edu). $(6 / 00 ; \mathrm{r} 10 / 00 ; \mathrm{r} 1 / 01 ; \mathrm{r} 4 / 01)$

\section{8 th Conference on Weather Analysis and Forecasting and 14th Conference on Numerical Weather Prediction, 30 July-2 August 2001, Fort Lauderdale, Florida}

The 18th Conference on Weather Analysis and Forecasting (WAF) and 14th Conference on Numerical Weather Prediction (NWP), sponsored by the American Meteorological Society and organized by the AMS Committee on Weather Analysis and Forecasting, will be held 30 July-2 August 2001 at the Fort Lauderdale Marriott
Marina, Fort Lauderdale, Florida. These conferences are being held in conjunction with the AMS Ninth Conference on Mesoscale Processes.

Preliminary programs, registration, hotel and travel information will be posted on the AMS Web site (http:// www.ametsoc.org/AMS) in early March 2001. AMS recommends that attendees secure hotel reservations at the Ft. Lauderdale Marina Marriott by 22 June 2001. For reservations, contact the Marriott at (800) 433-2254 or (954463-4000). Please be sure to mention the American Meteorological Society to get the lower conference rates.

From 1966 to 1995, WAF and NWP conferences were held during consecutive years, with each group focused on separate topics. In 1996, the conferences were combined to increase the interactions and knowledge sharing between the two groups. During the past four years a number of different formats were tried to determine the proper mix of WAF/NWP interaction. In 1999, the WAF Committee recommended that the joint WAF/NWP conferences be held every year beginning in 2001 with the focus of the conference on only one or two specific topics. A significant goal of these conferences is to bring together data assimilation developers, modelers, and operational users to focus and discuss issues at a single forum. The topics for the 2001 WAF/NWP conference are data analysis, data assimilation, and their impacts on the forecast process.

The deadline for abstracts has passed. Abstracts were solicited on the following: presentations related to these issues include collection and assimilation of remotely sensed and in situ observations; operational data analysis procedures; numerical data assimilation schemes; current and future data analysis procedures; future data collection platforms; synoptic and mesoscale studies that use remotely sensed or new-technology sensor systems; initial condition uncertainties; objective/variational analysis techniques; future data assimilation transitions to operational centers; and operational use data analysis output for forecast development.

Authors of accepted presentations will be notified (via e-mail) by early March. A preprint volume is being prepared and authors of invited and accepted papers will be asked to contribute to this volume. Instructions for formatting extended manuscripts for the preprint volume will be posted on the AMS Web site. Camera-ready manuscripts (page length to be determined), including photos and diagrams, must be submitted by 1 May 2001 to AMS Headquarters. Page charges will be assessed to defray printing costs. Registrants will receive a preprint volume at the conference.

For more information contact William Burnett, Naval Meteorology and Oceanography Command, 1020 Balch Blvd., Stennis Space Ctr., MS 39529 (tel: 228-688-4766; fax: 228-688-5791; e-mail: burnettb@cnmoc.navy.mil). $(7 / 00 ; \mathrm{r} 8 / 00 ; \mathrm{r} 10 / 00)$ 
Ninth Conference on Mesoscale Processes, 30 July2 August 2001, Ft. Lauderdale, Florida

The Ninth Conference on Mesoscale Processes, sponsored by the American Meteorological Society and organized by the AMS Committee on Mesoscale Processes, will be held 30 July-2 August 2001 in Ft. Lauderdale, Florida. This year Mesoscale Processes will be collocated with the AMS Weather Analysis and Forecasting/Numerical Weather Prediction meeting, with which there will be several joint sessions.

Preliminary programs, registration, hotel and travel information will be posted on the AMS Web site (http:// www.ametsoc.org/AMS) in early March 2001. AMS recommends that attendees secure hotel reservations at the Ft. Lauderdale Marina Marriott by 22 June 2001. For reservations, contact the Marriott at (800) 433-2254 or (954463-4000). Please be sure to mention the American Meteorological Society to get the lower conference rates.

The theme of Mesoscale Processes meeting will be Mesoscale Prediction and will include sessions on: 1) Mesoscale data assimilation for numerical weather prediction and research applications; 2) The development of the mesoscale prediction models; 3 ) Improving physical parameterizations in mesoscale models; 4) Mesoscale predictability and ensembles; and 5) New insights regarding mesoscale structure based on recent field experiments and new observing platforms.

The deadline for abstracts has passed. Authors of accepted presentations will be notified (via e-mail) by early March. A preprint volume is being prepared and authors of invited and accepted papers will be asked to contribute to this volume. Instructions for formatting extended manuscripts for the preprint volume will be posted on the AMS Web site. Camera ready manuscripts (page length to be determined), including photos and diagrams, must be submitted by 1 May 2001 to AMS Headquarters. Page charges will be assessed to defray printing costs. Registrants will receive a preprint volume at the conference.

For additional information, please contact, Cliff Mass, Univ. of Washington, Dept. of Atmospheric Science, P.O. Box 351640, Seattle, WA (tel: 206-685-0910; fax: 206543-0308; e-mail: cliff@atmos.washington.edu). (7/00; r10/00; r2/01)

\section{Announcement}

\section{Workshop on Satellite Remote Sensing Applications, 13-14 October 2001, Madison, Wisconsin}

A workshop entitled "Satellite Remote Sensing Applications from the User Perspective" will be held on 13-14 October 2001 preceding the $11^{\text {th }}$ Conference on Satellite Meteorology. There will be a separate program committee for this workshop, composed of members from the industry; the National Weather Service; the National Environmental Satellite, Data, and Information Service; and the National
Aeronautics and Space Administration. There will be a separate workshop fee for those attending.

The focus of the workshop is on scientific remote sensing and GIS applications developed to address the needs of government agencies and the private sector (farming, forestry, fisheries, insurance) with particular focus on needs in Asia, Africa, and Latin America. The aim is to focus awareness of and promote the use of satellite remote sensing data by a broader end user community.

The process is a collaborative effort that often teams researchers from universities and government with end users from state and local government agencies or private sector interests to analyze requirements, derive valueadded products, and prototype scientific applications that enhance decision making, planning, and management and protection of resources. Presentations are envisioned to include areas such as disaster management, disease monitoring, hydrology, protection of natural resources, urban planning and precision agriculture, coastal zone management, fisheries, and forestry.

The organizing committee will entertain proposals from corporate members of the AMS for presentations on specific applications of remotely sensed data. For further information contact Robert Plante (fax: 301-925-0438; email: rplante@eos.hitc.com). (4/01)

\section{Call for Papers}

\section{1 th Conference on Satellite Meteorology and Oceanography, 15-18 October 2001, Madison, Wisconsin}

The 11th Conference on Satellite Meteorology and Oceanography, sponsored by the American Meteorological Society and organized by the AMS Committee on Satellite Meteorology and Oceanography, will be held 15-18 October 2001 in Madison, Wisconsin.

A preliminary program, registration, hotel and general information will be posted on the AMS Web site (http:// www.ametsoc.org/AMS) in early June 2001. AMS recommends that attendees secure hotel reservations at the Best Western Inn on the Park by 13 September 2001. For reservations, contact the Best Western Inn on the Park at (800) 279-8811 or (608) 257-8811.

As with the past two meetings, the conference will be an all poster format with a few invited oral overview presentations. The invited plenary presentations on topical issues of broad interest will be used to set the themes of each day. To provide authors with sufficient time to discuss their research and to foster closer interaction among attendees, all other papers will be posters. Each session or day will be concluded in plenary with an interactive discussion of poster topics and themes. The general themes for the conference are listed below. Poster papers are solicited to cover any of these five broad areas of interest: 1) Environmental Applications of Land and Oceanic Remote Sensing. Subject 
areas include hazard support activities (i.e., volcanoes, wildfires, etc.), coastal-zone monitoring, land and agricultural processes, ocean color, sea ice, altimetry, ocean surface winds and air-sea fluxes; 2) Climatology and Long-Term Satellite Data Studies. Subject areas include the measurement of trends in temperature, water vapor, precipitation, trace gases, etc., and measuring the global water cycle from space; 3) Operational Applications. Subject areas include real-time applications of POES and GOES measurements and products, satellite data assimilation techniques, forward models, NWP impact studies, tropical cyclone studies, mesoscale and severe weather studies, use of rapid scan datasets, etc.; 4) Retrieval of Atmospheric Profiles and Constituents. Subject areas include retrieval methods used for temperature and moisture profiles, ozone, aerosols, precipitation, cloud water, etc.; and 5) New Technology. Subject areas include both new satellites/sensors (i.e., GOES-11, MODIS, AMSU, GIFTS, SSMIS, TRMM, EOS, QuikSCAT, etc.) and new processing and retrieval techniques (i.e., neural networks, error analysis, multisensor techniques, hyperspectral imaging and retrievals, etc.)

The conference program committee especially invites students to be an integral part of the conference. Therefore, posters identified as student submissions (primary author) on the abstract will automatically be entered in a student poster contest, with cash prizes and certificates awarded at the conference. A panel of judges will select winners at the time of the poster viewing.

Please submit your abstract electronically via the Web by 1 May 2001 (refer to the AMS Web page at http:// www.ametsoc.org/AMS for instructions). An abstract fee of $\$ 60$ (payable by credit card or purchase order) is charged at the time of submission (refundable only if the abstract is not accepted). Please be sure to submit your abstract on or before the deadline date. Papers will not be accepted after the abstract deadline. At the end of the abstract, authors are required to specify which one of the five themes above best describes the focus of their poster. Electronic posters are encouraged, but the program committee requests that your submission includes these plans and what your requirements may be (AMS can only provide a limited amount of technical support and hardware). E-mailed acceptance letters will be sent by mid June 2001 .

Authors of accepted presentations will be notified (via e-mail) by early June. A preprint volume is being prepared and authors of invited and accepted papers will be asked to contribute to this volume. Instructions for formatting extended manuscripts for the preprint volume will be posted on the AMS Web site. Camera-ready manuscripts for the preprint must be submitted by 3 August 2001 to AMS Headquarters. Page charges will be assessed to defray printing costs. Registrants will receive the preprint volume at the conference.

For more information on the conference, please contact Christopher Velden, CIMSS, University of Wiscon-
sin-SSEC, 1225 West Dayton St., Madison, WI 53706, Attn: 11th SATMET (fax: 608-262-5974; e-mail: chrisv@ssec.wisc.edu). More information will also be regularly posted on the Web site: http://fermi.jhuapl.edu/ sat_met_ocean/. (10/00; r2/01)

\section{Call for Papers}

\section{Fourth Conference on Coastal Atmospheric and Oceanic Prediction and Processes, 6-9 November 2001, St. Petersburg, Florida}

The Fourth Conference on Coastal Atmospheric and Oceanic Prediction and Processes, sponsored by the American Meteorological Society and organized by the AMS Committee on Meteorology, Oceanography, and Hydrology of the Coastal Zone, will be held 6-9 November 2001 in St. Petersburg, Florida.

This fourth coastal conference is collocating with ECM (Estuarine and Coastal Modeling) and with ERF (Estuarine Research Federation). A day of joint sessions is anticipated.

AMS recommends that attendees secure hotel reservations at the Tradewinds Sirata Hotel by $\mathbf{2 8}$ September 2001. For reservations, contact the Tradewinds at (727) 363-5100. The conference program and registration information will be posted on the AMS Web site (http:// www.ametsoc.org/AMS) in mid June 2001.

The theme for this conference is "Unifying our knowledge and modeling of the coastal atmosphere-ocean environment for the 21 st century." Our goal is to bring research and operations together to discuss how to combine our knowledge of the atmosphere and the ocean to improve our ability to analyze and predict the coupled airocean system.

The conference will address research, development, and operational issues concerning the analysis and prediction of coastal atmosphere, ocean, and coupled atmosphere-ocean phenomena and processes. Since the conference meets jointly with ECM and ERF, and the former AMS Committee on Meteorology and Oceanography of the Coastal Zone is now the AMS Committee on Meteorology, Oceanography, and Hydrology of the Coastal Zone, papers on hydrological processes in the coastal zone are encouraged.

In particular, papers are solicited and encouraged in the following areas: 1) utilization and/or acquisition of observations in the coastal zone; 2) coastal air-ocean, airwave, and hydrological processes; 3) coastal air-ocean, air-wave, and hydrological modeling: research and operations; and 4) special session (on Tuesday) on the Coastal Data Exchange, which will be a follow-up to the Interactive Symposium on the Exchange of Operational and Research Coastal Oceanic, Atmospheric, and Hydrologic Observations and Model Products (that was held at the 81st AMS Annual Meeting in January 2001). Participants with 
additional suggestions are encouraged to contact either of the program chairpersons.

Please submit your abstract electronically via the Web by 4 May 2001 (refer to the AMS Web page at http:// www.ametsoc.org/AMS for instructions). An abstract fee of $\$ 60$ (payable by credit card or purchase order) is charged at the time of submission (refundable only if the abstract is not accepted). When submitting your abstract please indicate your preference for an oral or poster presentation. If your preference is for an oral presentation, indicate whether you will make the presentation using overheads or if you intend to make an electronic presentation.

Authors of accepted presentations will be notified (via e-mail) by mid June. A preprint volume is being prepared and authors of invited and accepted papers will be asked to contribute to this volume. Instructions for formatting extended manuscripts for the preprint volume will be posted on the AMS Web site. Camera ready manuscripts (page length to be determined), including photos and diagrams, must be submitted by 3 August 2001 to AMS Headquarters. Page charges will be assessed to defray printing costs. Registrants will receive a preprint volume at the conference.

For further information contact: Frank Aikman III, National Ocean Service, NOAA, 1315 East-West Highway, Silver Spring, MD 20910 (tel: 301-713-2809 x101; fax: 301-713-4501; e-mail: Frank.Aikman@noaa.gov),or Richard M. Hodur, NRL, 7 Grace Hopper Ave., Monterey, CA 93943-5502 (tel: 831-656-4788; fax: 831-656-4769; e-mail: hodur@nrlmry.navy.mil). (11/00)

\section{Call for Papers}

\section{Fourth Symposium on Fire and Forest Meteorology, 13-15 November 2001, Reno, Nevada}

The Fourth Symposium on Fire and Forest Meteorology, sponsored by the American Meteorological Society, and organized by the AMS Committee on Agricultural and Forest Meteorology, will be held 13-15 November 2001 in Reno, Nevada.

AMS recommends that attendees secure hotel reservations at the Atlantis Casino Resort Hotel by 6 October 2001. For reservations, contact the Atlantis at (800) 723-6500. The conference program and registration information will be posted on the AMS Web site (http://www.ametsoc.org/ AMS) in mid July 2001.

The theme of the symposium will be to share experiences, new techniques and technologies and/or changes in the areas of: 1) coupled fire-atmosphere modeling; 2) use of mesoscale meteorological models for short-range fire planning, including, but not limited to, application of the next generation fire danger rating system; 3) use and development of weather forecasts for prescribed fire planning and execution; 4) techniques in smoke management and air quality mitigation related to the new national fire policy and the EPA PM2.5 standards; 5) mid- and longrange forecasting for fire control and fire use planning; 6) operational and near-operational fire weather forecasting techniques-use of new technologies and resources; 7) weather applications for operational fire behavior assessment and forecasts; 8) use and assessment of climate forecasts in fire management planning; 9) impacts of weather and climate on wildfire and; 10) utilization of weather and climate information for wildfire decisionmaking. A joint session may be held with and organized by the AMS Committee on Societal Impacts. Participants with additional suggestions for the program are encouraged to contact the program chairpersons.

Please submit your abstract electronically via the Web by 1 June 2001 (refer to the AMS Web page at http:// www.ametsoc.org/AMS for instructions). An abstract fee of $\$ 60$ (payable by credit card or purchase order) is charged at the time of submission (refundable only if the abstract is not accepted).

Authors of accepted presentations will be notified (via e-mail) by mid July. A preprint volume is being prepared and authors of invited and accepted papers will be asked to contribute to this volume. Instructions for formatting extended manuscripts for the preprint volume will be posted on the AMS Web site. Camera ready manuscripts (page length to be determined), including photos and diagrams, must be submitted by 24 August 2001 to AMS Headquarters. Page charges will be assessed to defray printing costs. Registrants will receive a preprint volume at the conference.

For further program information contact either one of the Program Cochairpersons: Tim Brown, Desert Research Institute, 2215 Raggio Parkway, Reno, NV 89512 1095 (tel: 775-674-7090; fax: 775-674-7016; e-mail: tbrown@dri.edu) or Sue Ferguson, Forestry Sciences Lab, 4043 Roosevelt Way NE, Seattle, WA 98105-6497 (tel: 206-732-7828; fax: 206-732-7801; e-mail: sferguson@fs.fed.us). (1/01)

\section{AMS 2002 Meetings}

\section{2nd AMS Annual Meeting 13-18 January 2002 Orlando, Florida}

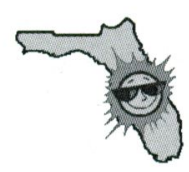

The 82nd Annual Meeting of the American Meteorological Society will be held 13-18 January 2002 at the Orlando Convention Center, Orlando, Florida.

The 82nd Annual Meeting is being organized around the broad theme of generating environmental information and services. Future improvements in forecast skill and user applications require incremental improvement in the continuum of activity from observation to prediction and data utilization, as well as the interfaces between developers and users. Two special interdisciplinary symposia are being organized to support the theme. 
The Symposium on Observations, Data Assimilation, and Probabilistic Prediction (cochairpersons: Robert Atlas and Eugenia Kalnay) will focus on the processes through which observations are assimilated and used to produce useful datasets and forecasts in the atmospheric, oceanic, and hydrologic sciences, with special emphasis on ensemble predictions. The Third Symposium on Environmental Applications: Facilitating the Use of Environmental Information (cochairpersons: Nick Keener and Lee Branscome) will address a broad array of services in the public and private sectors with an emphasis on the end use of environmental information. The full call for papers for each of these two symposia are provided below.

The meeting will also feature a president's symposium entitled "Society and the Society" (cochairpersons: Roger Pielke, Jr. and Richard Greenfield). This symposium will address how AMS can better communicate a synthesis of the science both for the membership and others, and how the AMS can help to further develop and communicate societal impacts research and mechanisms to support researchers, policymakers, and users of weather and climate information.

A set of presentations providing the "state of the science" within a few selected subdisciplines of our science is planned for this meeting, and it is expected to be the first of a series of such presentations at AMS annual meetings.

The meeting will include a few interdisciplinary conferences and symposia that have become traditional at the AMS Annual Meetings, including the 18th International Conference on Interactive Information Processing Systems (IIPS) for Meteorology, Oceanography, and Hydrology, the 13th Symposium on Global Change and Climate Variations, the 11th Symposium on Education, and the Sixth Symposium on Integrated Observing Systems. In addition, the meeting will include the 16th Conference on Probability and Statistics in the Atmospheric Sciences, the 15th Conference on Hydrology, the Fourth Conference on Atmospheric Chemistry: Urban, Regional, and Global Scale Impacts of Air Pollutants, and the Interactive Symposium on the Advanced Weather Interactive Processing System (AWIPS). Calls for papers for these conferences and symposia appear in this and future issues of the Bulletin, with the most up-to-date information always available on the AMS Web site (http://www.ametsoc.org/AMS).

In keeping with the new structure implemented with the 2001 Annual Meeting in Albuquerque, the meeting will make extensive use of poster sessions, including a "Grand Poster Event" with reception in addition to both formal and informal viewing times throughout the week. The oral sessions for the two broad symposia will include invited presentations intended to serve not only those carrying out active research in these areas but also attendees not working directly in these areas who want to become aware of the latest findings. As always, the annual meeting will host the largest exhibit anywhere of products and services in the atmospheric and related sciences, and a number of special functions will continue to make the AMS Annual Meeting one of the most productive weeks of the year for those seeking interactions with others in the field. (2/01)

\section{Call for Papers}

\section{Symposium on Observations, Data Assimilation, and Probabilistic Prediction, 13-18 January 2002, Orlando, Florida}

The Symposium on Observations, Data Assimilation, and Probabilistic Prediction, sponsored by the American Meteorological Society, will be held 13-18 January 2002 as part of the 82nd AMS Annual Meeting in Orlando, Florida. A preliminary program, registration, hotel, and general information will be posted on the Web at http:// www.ametsoc.org/AMS in early September 2001.

This symposium supports an interdisciplinary theme for the 82nd Annual Meeting associated with generation of environmental information and services. As such, it will be broad in scope, spanning the continuum from observation through prediction (or other utilization) in the atmospheric, oceanic, and hydrologic sciences. Papers are solicited on topics including, but not limited to, the following: more effective assimilation of the vast observational datasets now available; the emerging role of data assimilation in the oceans, land surface, atmospheric chemistry, hydrology, and the water cycle; observing systems forecast impact experiments; and strategies for adaptive observations. Ensemble prediction and assimilation is a special focus of this symposium as are other methods for statistical analysis and probabilistic predictions. Participants with additional suggestions for the program are encouraged to contact the program cochairpersons. This symposium is expected to have joint sessions with several other conferences and symposia at the annual meeting, including the 16th Conference on Probability and Statistics in the Atmospheric Sciences, the 15th Conference on Hydrology, the 13th Symposium on Global Change and Climate Variations, the Sixth Symposium on Integrated Observing Systems, and the Fourth Conference on Atmospheric Chemistry.

To leave time for longer oral presentations and panel discussions, and to reduce the need for parallel sessions, extensive use of poster sessions is planned. The posters will focus on recent results and specific applications in the areas noted above. The posters will be set up at the beginning of the meeting and be available for viewing all week, with two formal viewing times (one during the Grand Poster Event). It is anticipated that the space available for the posters will be adequate so that nearly all submitted abstracts can accepted.

Please submit your abstract electronically via the Web by 2 July 2001 (refer to the AMS Web page at http:// www.ametsoc.org/AMS for instructions). An abstract fee 
of $\$ 60$ (payable by credit card or purchase order) is charged at the time of submission (refundable only if the abstract is not accepted).

Authors of accepted presentations will be notified (via e-mail) by mid September. A preprint volume is being prepared and authors of invited and accepted papers will be asked to contribute to this volume. Instructions for formatting extended manuscripts for the preprint volume will be posted on the AMS Web site. Extended preprint manuscripts (page length to be determined), including photos and diagrams, must be submitted by 1 October 2001 to AMS Headquarters. Page charges will be assessed to defray printing costs. Registrants will receive a preprint volume at the conference.

For more information, contact the Program Chairpersons: Robert M. Atlas, NASA Data Assimilation Office, Building 33, Room C122, code 910.3, Goddard Space Flight Center, Greenbelt, MD 20771 (tel: 301-614-6140; fax: 301-614-6297; e-mail: atlas@ dao.gsfc.nasa.gov), or Eugenia Kalnay, Dept. of Meteorology, University of Maryland, 3431 Computer and Space Sciences Bldg., College Park, MD 20742 (tel: 301-405-5370; fax 301-3149482; e-mail: ekalnay@atmos.umd.edu). (2/01)

\section{Call for Papers}

\section{Third Symposium on Environmental Applications: Facilitating the Use of Environmental Information, 13-18 January 2002, Orlando, Florida}

The Third Symposium on Environmental Applications: Facilitating the Use of Environmental Information, sponsored by the American Meteorological Society, will be held 13-18 January 2002 as part of the 82nd AMS Annual Meeting in Orlando, Florida. A preliminary program, registration, hotel, and general information will be posted on the Web at http://www.ametsoc.org/AMS in early September 2001.

This symposium serves as one of the two interdisciplinary themes for the 82nd Annual Meeting, and as such will be broad in scope. Papers are solicited on topics in the application of meteorology, oceanography, and hydrology to the following: energy use and design (including wind and nuclear), architecture and construction, biometeorology and aerobiology, fire/forest, planned and inadvertent weather modification, air quality, coastal and ocean engineering, forensics, human health, water resources (quality and quantity), space weather, agriculture, insurance, weather derivatives, transportation [include meteorological aspects of the Intelligent Transportation System (ITS)], ecosystem and natural resource management, natural hazard mitigation strategies, business planning and analysis, and decision making under a sustainable development framework. Participants with additional suggestions for the program are encouraged to contact the program cochairpersons.
To leave time for longer oral presentations and panel discussions, and to reduce the need for parallel sessions, extensive use of poster sessions is planned. The posters will focus on recent results and specific applications in the areas noted above. The posters will be set up at the beginning of the meeting and be available for viewing all week, with two formal viewing times (one during the Grand Poster Event). It is anticipated that the space available for the posters will be adequate so that nearly all submitted abstracts can be accepted.

Please submit your abstract electronically via the Web by 2 July 2001 (refer to the AMS Web page at http:// www.ametsoc.org/AMS for instructions). An abstract fee of $\$ 60$ (payable by credit card or purchase order) is charged at the time of submission (refundable only if the abstract is not accepted).

Authors of accepted presentations will be notified (via e-mail) by mid September. A preprint volume is being prepared and authors of invited and accepted papers will be asked to contribute to this volume. Instructions for formatting extended manuscripts for the preprint volume will be posted on the AMS Web site. Extended preprint manuscripts (page length to be determined), including photos and diagrams, must be submitted by 1 October 2001 to AMS Headquarters. Page charges will be assessed to defray printing costs. Registrants will receive a preprint volume at the conference.

For more information, contact the Program Chairpersons: Nick Keener, Duke Energy, 526 S. Church St., P.O. Box 1244, Charlotte, NC 28202-1803 (tel: 704-594-0289; fax: 704-594-0556; e-mail: rnkeener@duke-energy.com) or Dr. Lee E. Branscome, Environmental Dynamics Research,7338 155 Place North, Palm Beach Gardens, FL 33418 (Tel: 561-744-4889; fax: 561-744-5098; e-mail: branscome@edrinc.com). (2/01)

\section{Call for Papers}

\section{8th International Conference on Interactive Information and Processing Systems (IIPS) for Meteorology, Oceanography and Hydrology, 13- 18 January 2002, Orlando, Florida}

The 18th International Conference on IIPS for Meteorology, Oceanography and Hydrology, sponsored by the American Meteorological Society and organized by the AMS Committee on Interactive Information and Processing Systems, will be held 13-18 January 2002 as part of the 82 nd AMS Annual Meeting in Orlando, Florida. A preliminary program, registration, hotel, and general information will be posted on the Web at http://www.ametsoc.org/AMS in early September 2001.

The theme of the 2002 IIPS conference will be "Assessing applications of technology in interactive processing systems to fully optimize operations and research in Meteorology, Oceanography and Hydrology." 
Abstracts will be solicited on the following IIPS topics: 1) Forecasting system technologies; 2) Observing system technologies; 3) Advancements/applications in Hydrology, Oceanography and Climatology; 4) Data and Information Handling; 5) Internet/Web Opportunities and Challenges; 6) Visualization; 7) European and other International Applications; 8) Data Access and Processing; and 9) Surface Transportation Applications. Special or joint sessions will be held with other conferences or symposia depending on common interests and objectives. A special session is planned with the AMS Symposium on the Advanced Weather Interactive Processing System (AWIPS).

Please submit your abstract electronically via the Web by 3 July 2001 (refer to the AMS Web page at http:// www.ametsoc.org/AMS for instructions). An abstract fee of $\$ 60$ (payable by credit card or purchase order) is charged at the time of submission (refundable only if the abstract is not accepted). When submitting your abstract please indicate your preference for an oral or poster presentation.

Authors of accepted presentations will be notified (via e-mail) by mid September. A preprint volume will be prepared and authors of invited and accepted papers will be asked to contribute to this volume. Instructions for formatting extended manuscripts for the preprint volume will be posted on the AMS Web site. Extended preprint manuscripts (page length to be determined), including photos and diagrams, must be submitted by 1 October 2001 to AMS Headquarters. Page charges will be assessed to defray printing costs. Registrants will receive a preprint volume at the conference.

For more information, contact the Program Chairperson: Terry C. Tarbell, PRC Inc., 1500 PRC Drive MS: 6N3, McLean, VA 22102; (tel: 703-883-5140; fax: 703-5561800; e-mail: tarbell_terry@prc.com;). (2/01)

\section{Call for Papers}

16th Conference on Probability and Statistics in the Atmospheric Sciences, 13-18 January 2002, Orlando, Florida

The 16th Conference on Probability and Statistics in the Atmospheric Sciences, sponsored by the American Meteorological Society and organized by the AMS Committee on Probability and Statistics in the Atmospheric Sciences, will be held 13-18 January 2002 as part of the 82nd AMS Annual Meeting in Orlando, Florida. A preliminary program, registration, hotel, and general information will be posted on the Web at http://www.ametsoc.org/AMS in early September 2001.

Papers are solicited on all aspects of probability and statistics in the atmospheric sciences, including but not limited to, observations and data assimilation, ensemble prediction, weather forecasting, climate variations and forecasting, environmental applications, data display and analysis, spatial and space-time statistics, time series, fore- cast evaluation, weather derivatives, and statistical aspects of global change, hydrology, atmospheric chemistry, and air pollution.

Please submit your abstract electronically via the Web by 3 July 2001 (refer to the AMS Web page at http:// www.ametsoc.org/AMS for instructions). An abstract fee of $\$ 60$ (payable by credit card or purchase order) is charged at the time of submission (refundable only if the abstract is not accepted). When submitting your abstract please indicate your preference for an oral or poster presentation. Authors of accepted presentations will be notified (via email) by mid September.

A preprint volume is being prepared and authors of invited and accepted papers will be asked to contribute to this volume. Instructions for formatting extended manuscripts for the preprint volume will be posted on the AMS Web site. Extended preprint manuscripts (page length to be determined), including photos and diagrams, must be submitted by 1 October 2001 to AMS Headquarters. Page charges will be assessed to defray printing costs. Registrants will receive a preprint volume at the conference.

For more information, contact the Program Chairperson: Robert E. Livezey, (tel: 301-763-8000, extension 7527; e-mail: Bob.Livezey@noaa.gov) (2/01; r3/01)

\section{Call for Papers}

\section{5th Conference on Hydrology, 13-18 January 2002, Orlando, Florida}

The 15th Conference on Hydrology, sponsored by the American Meteorological Society and organized by the AMS Committee on Hydrology, will be held 13-18 January 2002 as part of the 82nd AMS Annual Meeting in Orlando, Florida. A preliminary program, registration, hotel, and general information will be posted on the Web at http://www.ametsoc.org/AMS in early September 2001.

Session topics will include the following: 1) heavy precipitation and flash flooding; 2) land-atmosphere interactions; 3) hydrologic modeling; 4) seasonal to interannual water resources forecasting; and 5) remote sensing of hydrologic processes.

Please submit your abstract electronically via the Web by 5 July 2001 (refer to the AMS Web page at http:// www.ametsoc.org/AMS for instructions). An abstract fee of $\$ 60$ (payable by credit card or purchase order) is charged at the time of submission (refundable only if the abstract is not accepted). When submitting your abstract please indicate your preference for an oral or poster presentation.

Authors of accepted presentations will be notified (via e-mail) by mid September. A preprint volume is being prepared and authors of invited and accepted papers will be asked to contribute to this volume. Instructions for formatting extended manuscripts for the preprint volume will be posted on the AMS Web site. Extended preprint manuscripts (page length to be determined), including photos 
and diagrams, must be submitted by 1 October 2001 to AMS Headquarters. Page charges will be assessed to defray printing costs. Registrants will receive a preprint volume at the conference.

For more information, contact the Chairperson: James A. Smith, Dept. of Civil and Environmental Engineering, Princeton Univ., Princeton, NJ 08544 (tel: 609 258-4615; fax: 608 258-2799; e-mail jsmith@princeton.edu). (2/01; $\mathrm{r} 3 / 01)$

\section{Call for Papers}

\section{3th Symposium on Global Change and Climate} Variations, 13-18 January 2002, Orlando, Florida

The 13th Symposium on Global Change and Climate Variations, sponsored by the American Meteorological Society, organized with support by the AMS Committee on Climate Variations, will be held as a part of the $82 \mathrm{nd}$ AMS Annual Meeting, 13-18 January 2002 in Orlando, Florida. A preliminary program, registration, hotel, and general information will be posted on the Web at http:// www.ametsoc.org/AMS in early September 2001.

The 13th Symposium on Global Change and Climate Variations will be devoted to advances in our understanding of decadal-to-centennial and seasonal-to-interannual climate variability and changes. Areas to be addressed in the 13th Symposium on Global Change and Climate Variations include: climate modeling; variability and change in the observed record; climate forcing factors such as land surface modifications, aerosols, and greenhouse gases; land surface and hydrology interactions with the climate system; climate change detection; and variability and changes in the paleoclimate record. A special session is planned on climate model diagnosis: tools and techniques. Papers for this session should address one of the following: new methods of accessing and manipulating large data sets, creative techniques that reveal systematic errors in climate models, model intercomparison, or methods that suggest the causes of model errors. Additional areas of emphasis for the symposium are likely in support of the Annual Meeting theme.

Please submit your abstract electronically via the Web by 5 July 2001 (refer to the AMS Web page at http:// www.ametsoc.org/AMS for instructions). An abstract fee of $\$ 60$ (payable by credit card or purchase order) is charged at the time of submission (refundable only if the abstract is not accepted). Due to the large numbers of abstract submissions in recent symposiums, authors are strongly encouraged to submit only one oral presentation, with additional papers submitted as posters. If a primary author submits multiple oral presentations, the Program Committee reserves the right to designate one or more of the additional papers for poster presentation.

Authors of accepted presentations will be notified (via e-mail) by mid September. A preprint volume will be pre- pared and authors of invited and accepted papers will be asked to contribute to this volume. Instructions for formatting extended manuscripts for the preprint volume will be posted on the AMS Web site. Extended preprint manuscripts (page length to be determined), including photos and diagrams, must be submitted by 1 October 2001 to AMS Headquarters. Page charges will be assessed to defray printing costs. Registrants will receive a preprint volume at the conference.

For further information please contact the Program Chairperson, David R. Easterling, NOAA/National Climatic Data Center, 151 Patton Avenue, Asheville, NC 28801, 828-271-4675, (fax: 828-271-4328, e-mail: David.R.Easterling@noaa.gov. (2/01)

\section{Call for Papers}

\section{1 th Symposium on Education, 13-18 January 2002, Orlando, Florida}

The 11th Symposium on Education, sponsored by the American Meteorological Society and organized by the AMS Commission on Education and Human Resources, will be held 13-18 January 2002 as part of the 82nd AMS Annual Meeting in Orlando, Florida. A preliminary program, registration, hotel, and general information will be posted on the Web at http://www.ametsoc.org/AMS in early September 2001.

The theme for the Symposium on Education will be "Creating Opportunities in Educational Outreach through the Atmospheric and Oceanic Sciences." There will be both oral and poster sessions for K-12 and university education outreach activities. Papers related to diversity and human resource issues will also be accepted. There will be a special session on outreach programs pertaining to physical oceanography and air-sea interaction.

Please submit your abstract electronically via the Web by 1 June 2001 (refer to the AMS Web page at http:// www.ametsoc.org/AMS for instructions). An abstract fee of $\$ 60$ (payable by credit card or purchase order) is charged at the time of submission (refundable only if the abstract is not accepted). When submitting your abstract please indicate your preference for an oral or poster presentation.

Authors of accepted presentations will be notified (via e-mail) by mid September. A preprint volume is being prepared and authors of invited and accepted papers will be asked to contribute to this volume. Instructions for formatting extended manuscripts for the preprint volume will be posted on the AMS Web site. Extended preprint manuscripts (page length to be determined), including photos and diagrams, must be submitted by 1 October 2001 to AMS Headquarters. Page charges will be assessed to defray printing costs. Registrants will receive a preprint volume at the conference.

For more information, contact the Program Chairpersons: David R. Smith (tel: 410-293-6553; e-mail: 
drsmith@usna.edu) or Rajul Pandya, West Chester Univ., Dept. of Geology and Astronomy, West Chester, PA (tel: 610-436-2213; e-mail: rpandya@wcupa.edu. (2/01; r4/01)

\section{Call for Papers}

\section{Sixth Symposium on Integrated Observing Systems, 13-18 January 2002, Orlando, Florida}

The Sixth Symposium on Integrated Observing Systems, sponsored by the American Meteorological Society, will be held 13-18 January 2002 as part of the 82nd AMS Annual Meeting in Orlando, Florida. A preliminary program, registration, hotel, and general information will be posted on the Web at http://www.ametsoc.org/AMS in early September 2001.

The symposium will include all aspects of the regional and global heterogeneous observing systems, and the assimilation systems that are used to combine and use the data for various disciplines. Joint sessions are planned between this symposium and the Symposium on Observations, Data Assimilation, and Probabilistic Prediction.

Papers are solicited in the following areas: 1) Advances in ocean observing This session will include surface systems, such as buoys, underwater systems including acoustic sensing, sounders such as XBTs, and programs to coordinate global ocean sensing; 2) Advances in satellite observing This includes sensing systems planned for future polar orbiters and for geostationary systems. All types of systems, such as imagers, microwave and infrared radiometers, and lidars are invited; 3) Advances in in situ sensing This session includes the new generation of automated aircraft and balloons that can be used for atmospheric and ocean sensing. Sensing systems on research aircraft are included. It also will have papers on advances in surface sensing, such as automated surface stations, as well as new sounding technologies; 4) Advances in ground based remote sensing Radar, surface-based radiometry, lidars and other ground-based remote sensors will be the subject of this session; 5) Advances in GPS based observing This session includes both ground based and satellite based uses of GPS satellites to retrieve atmospheric and ocean surface fields; 6) Assimilation and analysis The discipline of combining different types of observations, irregularly distributed in time and space, will be the subject of this session; and 7) Testing and simulation of observing systems Development of the composite observing system of the future will require testing, calibration and validation of observing systems. It will also require simulations to determine the role of the various observing systems. Participants with additional suggestions for the program are encouraged to contact the program chair.

Please submit your abstract electronically via the Web by 6 July 2001 (refer to the AMS Web page at http:// www.ametsoc.org/AMS for instructions). An abstract fee of $\$ 60$ (payable by credit card or purchase order) is charged at the time of submission (refundable only if the abstract is not accepted).

Authors of accepted presentations will be notified (via e-mail) by mid September. A preprint volume is being prepared and authors of invited and accepted papers will be asked to contribute to this volume. Instructions for formatting extended manuscripts for the preprint volume will be posted on the AMS Web site. Extended preprint manuscripts (page length to be determined), including photos and diagrams, must be submitted by 1 October 2001 to AMS Headquarters. Page charges will be assessed to defray printing costs. Registrants will receive a preprint volume at the conference.

For more information, contact the Program Chairperson: Alexander MacDonald R/E/FS, NOAA/FSL, 325 S. Broadway, Boulder, CO 80303; (tel: 303-497-6378; fax: 303-497-6821; e-mail: macdonald@fsl.noaa.gov). (2/01)

\section{Call for Papers}

\section{The Fourth Conference on Atmospheric Chemistry: Urban, Regional, and Global Scale Impacts of Air Pollutants, 13-18 January 2002, Orlando, Florida}

The Fourth Conference on Atmospheric Chemistry: Urban, Regional, and Global Scale Impacts of Air Pollutants, sponsored by the American Meteorological Society and organized by the AMS Committee on Atmospheric Chemistry, will be held 13-18 January 2002 as part of the 82nd AMS Annual meeting in Orlando, Florida. A preliminary program, registration, hotel, and general information will be posted on the Web at http://www.ametsoc.org/ AMS in early September 2001.

This symposium will address the impacts of air pollutants both gases and aerosols on urban, regional, and global scale that atmospheric chemists and meteorologists are currently concerned with in tropospheric chemistry. Fundamental aspects of atmospheric chemistry and its integration with urban, regional, and global scale modeling and measurement will be addressed. Contributions within the general areas of atmospheric chemistry are also welcomed.

Specific topical areas are sought including: 1) history of atmospheric chemistry; 2) tropospheric aerosols-chemistry and radiative properties; 3 ) field studies examining urban and regional scale oxidant and aerosol production; 4) air pollution impacts on the biosphere and carbon cycles; 5) aircraft and remote sensing of atmospheric trace gases and aerosols; 6) boundary layer nighttime chemical processes; 7) heterogeneous chemical reactions in clouds; 8) stratospheric heterogeneous chemistry and stratospheretroposphere exchange; 9) development of real-time and near real-time air quality modeling that uses integration of measurement on urban and regional scales; 10) advances in instrumentation for aerosol and trace gas measurements; and 11) impacts of anthropogenic and natural halogen 
sources on urban and regional chemistries. Poster presentations from undergraduate and graduate students involved in atmospheric chemistry studies and internships are invited for the joint session with the 11th Symposium on Education. Participants with additional suggestions for the program are encouraged to contact the program chairperson.

Please submit your abstract electronically via the Web by 6 July 2001 (refer to the AMS Web page at http:// www.ametsoc.org/AMS for instructions). An abstract fee of $\$ 60$ (payable by credit card or purchase order) is charged at the time of submission (refundable only if the abstract is not accepted). When submitting your abstract please indicate your preference for an oral or poster presentation. Authors of accepted presentations will be notified (via e-mail) by mid-September.

A preprint volume is being prepared and authors of invited and accepted papers will be asked to contribute to this volume. Instructions for formatting extended manuscripts for the preprint volume will be posted on the AMS Web site. Extended preprint manuscripts (page length to be determined), including photos and diagrams, must be submitted by 1 October 2001 to AMS Headquarters. Page charges will be assessed to defray printing costs. Registrants will receive a preprint volume at the conference.

For further information contact Jeffrey S. Gaffney, Argonne National Laboratory, Bldg. 203/ER, Argonne, IL 60439 (tel: 630-252-5178; fax: 630-252-7415; e-mail: gaffney@anl.gov). (2/01)

\section{Call for Papers}

\section{Interactive Symposium on the Advanced Weather Interactive Processing System (AWIPS), 13- 18 January 2002}

As part of the 82nd AMS Annual Meeting, 13-18 January 2002 in Orlando, Florida, the AMS Board for Operational Government Meteorologists, AMS Committee on Interactive Information and Processing Systems, the AMS Committee on Weather Analysis and Forecasting, and the National Weather Association are cosponsoring an AWIPS interactive symposium.

A preliminary program, registration, hotel, and general information will be posted on the AMS Web site (http://www.ametsoc.org/AMS) in late September 2001. Oral presentations, poster presentations, and software demonstrations on AWIPS workstations will be solicited. The theme of the 2002 symposium is "Leveraging AWIPS to Maximize Our Nation's Forecast and Warning Support".

The primary purposes of this symposium are three-fold: to provide a forum for the exchange of status, plans, and concepts for AWIPS in operational use; to increase communication and collaboration among operational users of AWIPS and the hydrometeorological community; and an opportunity to demonstrate AWIPS capabilities.

Presentations and papers are solicited in the follow- ing areas: Overview of AWIPS; Visualization; Data Handling; Local Modeling; Internet/Web Opportunities and Challenges; Operational Meteorological and Hydrological Applications; Specialized Uses; Interactive Forecast Preparation System; Locally Written Applications, and Education and Training.

The deadline for abstracts is 6 July 2001. Abstracts are now submitted electronically (refer to the AMS web site for more details). AMS will provide instructions to authors of accepted papers. Camera-ready manuscripts (page length to be determined), including photos and diagrams, must be submitted by 1 OCTOBER 2001 to AMS Headquarters. Page charges will be assessed to defray printing costs. Registrants will receive a preprint volume at the conference.

For further information or suggestions to enhance the symposium, please contact a member of the Program Committee:

- Ken Carey, Air Force Studies and Analyses Agency (AFSAA/SATG), 1570 Air Force Pentagon, Washington DC 20330-1570 (tel: 703-588-8626; fax 703-5880220; e-mail: kenneth.carey@ pentagon.af.mil)

- Terry Tarbell, PRC Inc., 1500 PRC Drive, McLean, VA 22102-5050 (tel: 703-883-5140; fax 703-5561800; e-mail: tarbell_terry@prc.com)

- Bill Burnette, Naval Meteorology and Oceanography Command,1020 Balch Blvd, Stennis Space Center, MS 39529-5001 (tel: 228-688-4766; fax: 228-6885791; e-mail: burnettb@cnmoc.navy.mil)

- Dan McCarthy, NOAA/NWS/SPC, 1313 Halley Circle, Norman, OK 73069 (tel: 405-579-0747; fax 405-579-0700, e-mail Daniel.McCarthy@spc.noaa.gov) - Dan Nietfeld, National Weather Office Forecast Office, 6365 North Osborne Dr. W., Hastings, NE 68901-9120 (tel: 402-462-2127; fax: 402-462-2746; e-mail: Dan.Nietfeld@noaa.gov). (2/01; r4/01)

\section{Call For Papers}

\section{5th Conference on Agricultural and Forest Meteorology, 20-24 May 2002, Norfolk, Virginia}

The 25th Conference on Agricultural and Forest Meteorology sponsored by the American Meteorological Society and organized by the AMS Committee on Agricultural and Forest Meteorology will be held 20-24 May 2002 in Norfolk, Virginia. The conference will be held concurrently with the AMS Fourth Symposium on the Urban Environment and the 12th Joint Conference on the Applications of Air Pollution Meteorology with the Air and Waste Management Association.

Contributions are solicited on all topics related to agricultural and forest meteorology, and to those related to meteorological aspects of other natural ecosystems. Appropriate topics include, but are not limited to, theoreti- 
cal and applied studies of interactions between the atmosphere and land surface; evapotranspiration and the energy balance; modeling and measurement of meteorological processes related to agriculture and forestry; canopy micrometeorology; weather data networks and requirements; and the effects of weather and climate on agriculture and forestry (including climate change).

Presentations will be either oral or poster. We urge authors to limit themselves to a single oral presentation on a given topic, with complementary papers given as posters. Joint sessions are planned on canopy-atmosphere coupling (measurement, parameterization and modeling), urban forests, and dispersion over rough surfaces with the Symposium on the Urban Environment; on dispersion over and through canopies with the Conference on Air Pollution Meteorology; and on plant/atmosphere chemical interactions (sources and sinks of chemical species) in collaboration with the AMS Committee on Atmospheric Chemistry. Proposals for other such sessions or panel discussions are welcome (please contact the chairperson).

Awards will be given to students for the best papers and posters. In order to be considered for the competition, students should indicate their intent to participate in this competition when they submit their abstract.

The deadline for abstracts is $\mathbf{1 5}$ November $\mathbf{2 0 0 1}$. Abstracts are now submitted electronically (visit the AMS Web site at http://www.ametsoc.org/AMS or see the Bulletin for instructions on this electronic procedure). Extended abstracts will be due by $\mathbf{2 8}$ February 2002 for publication in the preprint volume. For additional information, please contact the Program Chairperson: Brian Amiro, Canadian Forest Service, Northern Forestry Centre, 5320 - 122 Street, Edmonton, AB, Canada, T6H 3S5. (e-mail: bamiro@nrcan.gc.ca; tel: 780-435-7217; fax: 780435-7359) (4/01)

\section{Call for Papers}

\section{2th Joint Conference on the Applications of Air Pollution Meteorology with the Air and Waste Management Association (A\&WMA), 20-24 May 2002, Norfolk, Virginia}

The 12th Joint Conference on the Applications of Air Pollution Meteorology with the Air \& Waste Management Association, sponsored by the American Meteorological Society and organized by the AMS Committee on the Meteorological Aspects of Air Pollution, will be held 2024 May 2002 in Norfolk, Virginia. The meeting will be held concurrently with the AMS Fourth Symposium on the Urban Environment and the 25th Conference on Agricultural and Forest Meteorology.

The conference will cover fundamental aspects of dispersion (theories, laboratory experiments, numerical experiments, field observations), air pollution meteorology, air quality applications, and chemistry.
The general topical areas include: gaseous and aerosol dispersion, deposition, factors affecting the dispersion environment (turbulence, boundary layer processes, source conditions, etc), terrain and building influences, chemistry, and instruments and measurement systems.

Both poster and oral presentations are solicited in the above areas as well as on the following specific topics: 1) dispersion in convective and stable boundary layers; 2) dispersion about buildings and obstacles; 3 ) flow and dispersion in coastal and complex terrain; 4) meso- and regional-scale dispersion; 5) photochemical and other chemistry-oriented air quality models; 6) particulates, aerosols, and related phenomena; 7) instantaneous and accidental releases; 8) concentration fluctuations, model uncertainty and evaluation; 9) integrated modeling/measurement systems for emissions and air quality predictions; and 10) advanced modeling techniques for dispersion on all scales (e.g., Lagrangian particle models, large-eddy simulations, etc.). In addition, joint sessions are planned with the Symposium on the Urban Environment on: dispersion at building, street canyon, and urban scales; meteorology and air flow on urban scales; the urban VTMX program; urban emission inventories; and urban and regional scale ozone. With the Agricultural and Forest Meteorology Conference, joint sessions are planned on dispersion over and through canopies, and deposition to canopies.

The deadline for abstracts is $\mathbf{1 5}$ November 2001. Abstracts are now submitted electronically (visit the AMS Web site at http://www.ametsoc.org/AMS or see the AMS Bulletin for instructions on this electronic procedure). AMS will provide instructions to authors of accepted papers. Extended abstracts will be due by $\mathbf{2 8}$ February $\mathbf{2 0 0 2}$ for publication in the preprint volume. Page charges will be assessed to defray printing costs. Registrants will receive a preprint volume at the conference.

For further information contact: Jeffrey C. Weil, CIRES, University of Colorado, CB 216, Boulder, CO 80309 (tel: 303-497-8907, fax: 303-497-8171, e-mail: weil@ucar.edu). (4/01)

\section{Call for Papers}

\section{Fourth Symposium on the Urban Environment, 20- 24 May 2002, Norfolk, Virginia}

The Fourth Symposium on the Urban Environment, sponsored by the American Meteorological Society, and organized by the AMS Board on the Urban Environment will be held 20-24 May 2002 in Norfolk, Virginia at the Sheraton Norfolk Hotel. The symposium is being held in conjunction with the $25^{\text {th }}$ Conference on Agricultural and Forest Meteorology and the $12^{\text {th }}$ Joint Conference on the Applications of Air Pollution Meteorology with the Air and Waste Management Association. A number of joint sessions are planned between the conferences. 
Papers and posters are invited on all subjects dealing with the urban atmosphere. Observational, modeling, theoretical, and applied studies are all welcome. Sessions will be held to cover themes of urban vegetation/atmosphere interactions, turbulent transport and dispersion processes (in urban areas and around buildings), urban air quality (urban airshed modeling and urban air chemistry experiments), measurement challenges and observation techniques in urban environments, urban winds and circulation systems, the energy and water balance of cities, the urban heat island effect and its possible contamination of longterm air temperature records, remote sensing of urban meteorological variables, heat waves and urban biometeorology, cities as agents of global change, the urban carbon balance, building climate, road climatology, examples of planning and policy changes resulting from urban climate research, urban rainstorms and other effects on weather, and weather forecasting for urban areas and city dwellers.

A number of special sessions, which include results and opportunities associated with intensive urban campaigns (e.g. BUBBLE, ESCOMPTE/URBCAP, URBAN-VTMX, Urban LTER sites, URGENT, etc.), also are planned. Suggested themes for Joint Sessions include (with Agricultural and Forest Meteorology): canopy-atmosphere coupling (measurement, parameterization and modelling); urban forests; dispersion over rough surfaces; and (with Air Quality) flow and dispersion studies at building, street canyon and urban scales; model comparisons for urban atmospheric flow and dispersion; the VTMX program; urban radiation and chemical rate coefficients; urban emissions inventories; and urban and regional scale ozone. Proposals for other such sessions or for panel discussions are welcome; please contact the Program Chairs as soon as possible and certainly before the due date for abstracts. Participants with additional suggestions for the programs are encouraged to contact the program chairperson.

Awards will be given to students for the best papers and posters. In order to be considered for the competition, students should indicate their intent to participate in this competition when they submit their abstract.

The deadline for abstracts is $\mathbf{1 5}$ November 2001. Abstracts are now submitted electronically (visit the AMS Web site at http://www.ametsoc.org/AMS for instructions on this electronic procedure). Authors of accepted abstracts will be notified by early January 2002 . A preprint volume is planned and authors of accepted abstracts are encouraged to contribute to this volume. Extended abstracts will be due 28 February 2002.

For additional information, please contact the Program Chairs: Sue Grimmond (e-mail: grimmon@indiana.edu) or James Voogt (e-mail: javoogt@ julian.uwo.ca). (4/01)

\section{Other 2001 Meetings Of Interest}

\section{The Oceanography Society's (TOS) Biennial Scientific Meeting, 2-5 April 2001, Miami Beach, Florida}

The Biennial Scientific Meeting of the Oceanography Society will be held 2-5 April 2001, at the Miami Beach Convention Center in Miami Beach, Florida. The American Meteorological Society is a cooperating organization.

This program will span a broad range of topics in oceanography and the day-by-day session themes will allow a focus on interdisciplinary topics and research enabled through advanced technology.

The themes are 1) Air-Sea Interactions; 2) The Water Column; and 3) The Seafloor. The meeting format will include plenary sessions of invited and contributed talks on the daily session themes and contributed posters focusing on, but not limited to, the session topics.

This meeting will be particularly special, as it will be held in conjunction with the Oceanology International Americas 2001 Conference and Exhibition. This larger meeting format is well known for its wealth of exhibits related to ocean science and technology. For further information refer to the TOS Web site at http://www.tos.org. $(2 / 01)$

\section{Announcement}

23rd Annual National Hurricane Center Conference, 9-13 April 2001, Washington, DC

The 23rd Annual National Hurricane Center Conference will be held 9-13 April 2001 in Washington, DC at the Omni Shoreham Hotel. For more information, please call 850-906-9224, e-mail: mail@HurricaneMeeting.com or visit our web site at: www.HurricaneMeeting.com. (4/01)

\section{Announcement}

The WCRP/SCOR Workshop on Intercomparison and Validation of Ocean-Atmosphere Flux Fields, 21-25 May 2001, Washington, D.C.

The WCRP/SCOR Workshop on Intercomparison and Validation of Ocean-Atmosphere Flux Fields, to be held 21-25 May 2001 in Washington, DC, is the second meeting encouraging interaction and dialogue between the diverse scientific communities involved in producing and using air-sea fluxes. The American Meteorological Society is a cooperating organization.

Following the landmark First WCRP Workshop on AirSea Flux Fields for Forcing Ocean Models and Validating GCMs held at ECMWF, Reading, in October 1995, a joint WCRP/SCOR Working Group on Air-Sea Fluxes was set up to continue to foster interdisciplinary consultations in this area, and to catalogue and keep under review available surface flux and flux-related data sets. The Final Report of 
the Working Group is a substantial document assessing the present state of the art in regard to air sea flux determination ("Intercomparison and Validation of Ocean-Atmosphere Energy Fluxes" shortly to be published in the WCRP report series). The report can be accessed at http:// www.soc.soton.ac.uk/JRD/MET/WGASF/get_report.html.

Goals of the Workshop are the following:

- bring together the different scientific communities interested in air-sea fluxes and working on their development and application through modeling, remote sensing and in-situ measurements;

- stimulate discussion by a wide spectrum of the research community on the issues raised in the WGASF report, consider group recommendations and discuss priorities for future activities in the areas identified as significant knowledge gaps;

- consider the need for any continuing internationally coordinated initiative in air-sea flux studies.

A focus of the Workshop will be to summarize recent developments of in-situ, remotely sensed and model output fields for flux and flux related parameters. Particular attention will be devoted to assessing the uncertainties inherent in the various fields. Although primarily concerned with global-scale flux climatologies, emphasis will also be given to the development of flux parameterizations, and to field experiments and other high quality in-situ flux data, designed to refine those parameterizations. Contributions dealing with global and basin-scale energy balances, and the variability of ocean-atmosphere fluxes will also be welcome.

The workshop is intended to promote feedback and encourage dialogue between the producers and users of surface flux and related data. Following an introductory presentation of the WGASF report, sessions will address the key topics using a combination of invited, oral and poster papers. Break-out groups will be tasked with considering an effective and balanced strategy for making further progress in the study and utilization of ocean-atmosphere fluxes.

The deadline for abstract has passed. For further information about the workshop refer to the following Web sties http://www.soc.soton.ac.uk/JRD/MET/WGASF or http://www.sail.msk.ru/workshop. (3/01; r4/01)

\section{Announcement}

\section{GOES Users Conference, 22-25 May 2001, Boulder, Colorado}

The GOES Users Conference will be held from 22-25 May 2001 in Boulder, Colorado, at the NIST Auditorium.

The goals of the conference are to: 1) inform users of future capabilities and potential applications; 2) determine user needs for new products, distribution of GOES data, data archiving and access to stored data, instruments of oppor- tunity, access to sample data prior to launch of next series, future training; 3 ) assess user and societal benefits of future systems; and 4) develop methods to improve communication between NESDIS and the GOES user community.

For more information visit: http://www.osd.noaa.gov/ Conference/. For online registration visit: http:// www.boulder.nist.gov/blconf.htm. For any other information contact the Program Chairperson: James Gurka of NOAA/NESDIS (e-mail: jgurka@nesdis.noaa.gov. (3/01; $\mathrm{r} 4 / 01)$

\section{5th Congress of the Canadian Meteorological and Oceanographic Society, 27 May-1 June 2001, Winnipeg, Manitoba, Canada}

The 35th Congress of the Canadian Meteorological and Oceanographic Society (CMOS) will be held from 27 May-1 June 2001, at the Sheraton Hotel in Winnipeg, Manitoba, Canada. The theme of 35th CMOS Congress is Extreme Weather. The American Meteorological Society is a cooperating organization.

Papers are being solicited on all aspects of extreme weather events found globally such as severe thunderstorms, tornadoes, tropical cyclones, flooding, droughts, blizzards, etc. Particular emphasis should be placed on forecasting, impacts, warning and emergency preparedness, remote sensing, numerical, atmosphere-ocean interactions, and climate modeling and variability, as they relate to extreme weather. We welcome all presentations relating to this topic and additional related topics, which can tie into the overall theme. A preprint volume is being planned which will contain all accepted abstracts. The deadline for abstract submission has passed.

Contact Jay Anderson, Prairie Storm Prediction Centre, Suite 150123 Main Street, Winnipeg, MB, Canada R3C 4W2; (tel: 204-984-7923; fax: 204-984-0109; e-mail: Jay.Anderson@ec.gc.ca). (11/00)

\section{ITS American 11 th Annual Meeting, 4-7 June 2001, Miami Beach, Florida}

The ITS American is holding its 11th Annual Meeting in Miami Beach, Florida, the week of 4-7 June 2001.

For further information refer to Web site http:// www.itsa.org/ITS2000.nsf/Files/2001CallForPapers/\$file/ 2001CallForPapers.pf. (11/00)

\section{Seventh Topical Meeting on Meteorological Optics, 5-8 June 2001, Boulder, Colorado}

The Seventh Topical Meeting on Meteorological Optics will be held 5-8 June 2001 at the National Center for Atmospheric Research in Boulder, Colorado. The meeting covers original research on natural optical effects, mostly in the atmosphere, that canbe seen or photographed. The American Meteorological Society is a cooperating organization.

Papers were invited in the following areas: rainbows, ice crystal halos, glories, coronas and iridescence, sky 
color, refraction effects, contrast phenomena, and optics of lightning phenomena and auroras. Invited presentations on special topics include optics of lightning phenomena, auroras, minerals and gems, and aspects of biological luminescence and iridescence. One evening will consist of public lectures and demonstrations.

The deadline for abstracts has passed. Acceptance emails will be sent by 1 March 2001. Two-page camera ready preprints are due by 15 April 2001. Abstracts and preprints should be sent to Stanley David Gedzelman, Department of Earth and Atmospheric Sciences, City College of New York, New York, NY 10031, tel: 212-650-6470; fax: $212-$ 650-6482; e-mail: stan@scisun.sci.ccny.cuny.edu. (1/01; $\mathrm{r} 4 / 01)$

Canada Wave Phenomena III: Waves in Fluids from the Microscopic to the Planetary Scale, 1115 June 2001, Edmonton, Alberta, Canada

The Pacific Institute for the Mathematical Sciences, the Applied Mathematics Institute and the University of Alberta are pleased to announce that "Wave Phenomena III" will be held 11-15 June 2001 on the campus of the University of Alberta in Edmonton, Canada. This conference follows the highly successful "Wave Phenomena" and "Wave Phenomena II" meetings held in 1983 and 1992, respectively.

The wave concept is one that unifies many areas of science, and the underpinning mathematical theory of waves therefore finds an enormous spectrum of cross-disciplinary applications. Waves III will focus upon wave phenomena in such diverse disciplines as geophysics, oceanography, meteorology, astrophysics, physiology, and biology. This meeting will be held immediately after the 3rd Annual PIMS Fluid Dynamics Summer School (also to be held at the University of Alberta) in order that the next generation of scientists may benefit from the expertise that will be reflected in this gathering. Waves III Conference information, including a complete list of the 25 confirmed plenary speakers, can be found on the conference Web site at http:// waves3.math.ualberta.ca/.

The language of the conference is in English. The deadline for abstracts has passed.

For information not posted on at the conference Web site, you may send inquiries to the above address or by fax (780-492-6826), phone (780-492-5141), or e-mail (waves3@math.ualberta.ca).

\section{Earth System Processes Conference, 24-28 June 2001, Edinburgh, United Kingdom}

A joint meeting of the Geological Society of America and the Geological Society of London GSA and GSL, two of the oldest and largest organizations of earth scientists, are combining their resources to co-convene a broad, interdisciplinary meeting to discuss the present state of knowledge of Earth System Processes. For further details see the web page at www.geosociety.org/meetings/ edinburgh. Contacts: Ian Dalziel and Ian Fairchild (scientific content); Helen Wilson and Michael Stevens (administration / printed copies of second circular). (2/01)

International Symposium on Climate, the Environment and Societies in the New Millennium, 25-30 June 2001, Jerusalem, Israel

The International Symposium on Climate, the Environment and Societies in the New Millennium, sponsored by the International Geographical Union, Commission on Climatology and organized by the Israel committee, will be held 25-30 June 2001, Jerusalem, Israel. The American Meteorological Society is a cooperating organization.

The preliminary program consists of five major topics: 1) Climate variability and climate change on various geographical scales; 2) Synoptic climatology and climate forecasting, including extreme events; 3) Climatology and data base construction, including time series; 4) Applied climatology, including air pollution climatology; and 5) Past, present, and in particular, future trends in climatology.

Special sessions devoted to methodologies of analysis, modern climate services and their applications, remote sensing, GIS and future trends in climatology, may be arranged.

The deadline for submission of abstracts has passed. Camera-ready manuscripts of one page should be sent to E. H. Stinberger, Atmospheric Sciences Department, The Hebrew University, Jerusalem 91904, Israel (e-mail: HAVA@VMS.HUJI.AC.IL). Authors of accepted papers will be notified by February 2001. For further information contact J. Lomas, Israel Meteorological Society, P.O. Box 25 Bet-Dagan 50250, Israel (e-mail: agromet@ims.gov.il). $(9 / 00)$

\section{Call For Papers}

\section{XXIst International Congress of History of Science, Mexico City, Mexico, 8-14 July 2001}

Papers are requested on international aspects of the history of meteorology, broadly construed to include scientific, environmental, social, political and cultural issues. How did meteorology emerge as an international science? What tensions have existed between national weather services, national research styles, and international or global agendas? What are the social and/or cultural implications of trans-national research, education, and forecasting?

Participants may also wish to attend the inauguration of the new Commission on the History of Meteorology and participate in its governance. If circumstances warrant, the Commission will pursue publication options for the conference papers. The deadline for early registration has passed; Deadline for abstracts: 30 April 2001; Meeting dates: 8-14 July 2001; Conference web page: http:// www.smhct.org/default.htm. Please send your name, affiliation, paper title and brief abstract to: James R. Fleming, President, Commission on History of Meteorology, STS 
Program, 5881 Mayflower Hill, Colby College, Waterville, ME 04901. (e-mail: jrflemin@ colby.edu) (4/01)

\section{Announcement}

Eighth Assembly of the International Association for Meteorology and Atmospheric Sciences (IAMAS 2001), 10-18 July 2001, Innsbruck, Austria

The IAMAS Assembly in Innsbruck is structured around 11 themes, which are at the core of the IAMAS Sciences and the work of its 10 Commissions. The multitude of aspects to be discussed in the open scientific meetings is staggering and underlines the basic role the atmospheric sciences play in everyday life and in the planning for the future.

The themes are: 1) Climate and Climate Change, ICCL; 2) Climate Variability; 3) Land-surface Interactions; 4) Atmospheric Radiation; 5) Clouds and Precipitation; 6) Weather Systems; 7) Atmospheric Chemistry; 8) Middle Atmosphere (Stratosphere) Dynamics; 9) Middle Atmosphere (Stratosphere) Chemistry; 10) Planetary Atmospheres and their Evolution; and 11) Observing Systems and Data Assimilation.

The Program of the Innsbruck Assembly is augmented by two special Symposia. In the first the members of the Working Group I of the Intergovernmental Panel for Climate Change, IPCC, will report on the results leading to the Third Assessment Report. This will give IAMAS a first glimpse of the up-to-date scientific status of Climate Change.

The second happening is a joint venture between IAMAS and the International Association of Hydrology, IAHS. It highlights one of the basic measuring issues in Meteorology: the assessment of rainfall from convective cloud systems. Note that snow has been left out deliberately because it is even more complex.

The scientific reporting will be complemented by four Presidential Lectures by leaders in the field. During five noon hours (bring your own lunch) younger scientists will be given the opportunity to "reach for the ring". There will also be a special poster session for presentations not fitting too well into the structured program, but papers that should not be missed.

For further details contact, Professor Michael Kuhn, Institute of Meteorology and Geophysics, University of Innsbruck, Innrain 52, A-6020 Innsbruck, Austria, iamas@uibk.ac.at and http://meteo.uibk.ac.at. (3/01)

\section{Coastal Zone 01 (CZO1) Conference, 15-19 July 2001, Cleveland, Ohio}

Musical themes and the topics of concern to the coastal and ocean management community will come together at the Coastal Zone 01 (CZ01) Conference in Cleveland, Ohio, a Great Lakes coastal city and the home of the Rock and Roll Hall of Fame. This 12th Biennial International Symposium on Coastal and Ocean Management will take place 15-19 July 2001 at The Cleveland Convention Center.
CZ01 will feature important lessons learned by coastal managers around the world and models of successful partnerships, such as that established in the Great Lakes, where two sovereign nations jointly manage water and living resources of this great "inland sea." Cleveland offers an outstanding opportunity to examine how local and regional issues are connected to worldwide influences of culture and commerce, climate and biology.

Conference themes include Taking Care of Business, Sustainable Coastal Communities, Maritime Transportation and Commerce, People and the Coast, and Energy and the Environment. The deadline for abstracts has passed. For more information refer to the conference Web site at www.csc.noaa.gov/CZ2001. (10/00)

\section{Second International Conference on Fog and Fog Collection 15-20 July 2001, St. John's, New- foundland, Canada}

The Second International Conference on Fog and Fog Collection will be held at the Hotel Newfoundland, in St. John's, Newfoundland, Canada, 15-20 July 2001. The American Meteorological Society is a cooperating organization.

The conference will focus on the physics, chemistry, meteorology, forecasting, and remote sensing of fog; fog deposition and the interaction of fog with vegetation; dew research; fog collection projects in developing countries; and the negative effects of fog on commercial offshore activities. Conference sponsors include Canadian International Development Agency, Canadian Meteorological and Oceanographic Society, Environment Canada, International Development Research Centre, and the World Meteorological Organization.

A complete list of session topics as well as a list of sponsors and agencies endorsing the conference can be found on the Web at http://www.tor.ec.gc.ca/fog-conference/. The conference will also include special sessions on the negative impacts of fog on offshore activities (aviation, shipping, remote sensing, etc.) in the oceans of the world.

Please see the Web site address given above for answers to most queries. You may also write to Robert Schemenauer (Conference Chair) at the Conference on Fog and Fog Collection, P.O. Box 81541, 1057 Steeles Avenue West, Toronto, ON M2R 2X1, Canada (fax: 416-7394211; e-mail: robert.schemenauer@ec.gc.ca). (3/00; r5/00; $\mathrm{r} 12 / 00 ; \mathrm{r} 4 / 01)$

\section{Call for Papers}

First International Conference on Global Warming and The Next Ice Age, 19-24 August 2001, Halifax, Nova Scotia, Canada

The International Conference on Global Warming and The Next Ice Age, cosponsored by the Atmospheric Science Program at Dalhousie University and the Canadian Meteo- 
rological and Oceanographic will be held 19-24 August 2001 at Dalhousie University in Halifax, Nova Scotia, Canada. The American Meteorological Society is a cooperating organization.

The subject areas to be addressed at the Conference on Global Warming and The Next Ice Age include natural and anthropogenic climate change and variability, effect of variations in the solar constant, climate change in the Arctic, paleoclimate data analysis and model results, estimates and predictions of the next glacial period, interpretation of the observational record and comparison of model predictions of climate change with observations. The program will consist of invited and contributed oral and poster presentations with ample time reserved for discussions. One of the objectives of this conference is to provide a forum for an unfettered and lively discussion of the issues, controversial and otherwise, associated with the science of climate change.

Intention to attend and/or present a paper must have been e-mailed by 28 February 2001. Deadline for submission of short (up to a half page) abstracts is 1 April 2001. The authors of accepted abstracts would be asked to provide an extended abstract of up to four pages by 15 May 2001. A volume of reviewed extended abstracts will be published by the time of the conference.

A limited number of grants to cover a part of travel expenses for graduate students and scientists from developing countries, who otherwise would not be able to attend, will be available. Intention to attend and short abstracts should be submitted by e-mail to Petr.Chylek@noaa.gov with a copy to Glen.Lesins@Dal.Ca.

Further information concerning the conference location, registration procedures, accommodations, etc. can be fund by following the link at Web site www.atm.dal.ca. $(12 / 00 ; \mathrm{r} 4 / 01)$

\section{International Workshop on Physical Modeling of Flow and Dispersion Phenomena, 3-5 September 2001, Hamburg, Germany}

A workshop on will be held 3-5 September 2001 at Hamburg University in Hamburg Germany to explore and to discuss the latest achievements in physical modeling of flow and dispersion phenomena. It is intended to provide a forum for discussion of research results, information exchange and establishment/reactivation of personal contacts between wind tunnel or water flume laboratories around the world. The program will include presentations, discussions, and a poster session.

The workshop is intended to focus on physical modeling of environmental flow and dispersion phenomena. The subject of contributions may cover current topics like improvement or validation of boundary-layer modeling techniques, new measurement techniques and their application to the investigation of flow and dispersion phenomena, basic investigations of the structure of flow and dispersion phenomena in turbulent boundary layers, gen- eration of validation data for numerical flow and dispersion models, and application of physical modeling techniques (urban type flow and dispersion problems, odor dispersion, pedestrian wind comfort, ventilation of built-up areas, biogenic emissions, accidental releases, modeling of topographic effects, etc.)

The deadline for abstracts has passed. For further information, refer to the workshop web site www.mi.unihamburg.de/physmod2001. Authors will be informed on acceptance of their contributions by the end of March 2001. Full papers (about 8-10 pages) are due 1 June 2001. Accepted papers and posters will be published in an online preprint volume and, subject to acceptable reviews, published in a special edition of a major international journal.

For information not posted on the web site, contact Sabine Bartols, Meteorological Institute, University of Hamburg, Bundesstrasse 55, D-20146 Hamburg, Germany (tel: +49 4042838 5452; e-mail: physmod2001@dkrz.de). (2/01)

\section{The Fourth International Scientific Conference on the Global Energy and Water Cycle, 10-14 Seprember 2001, Paris, France}

The Fourth International Scientific Conference on the Global Energy and Water Cycle will be held at Collège de France, Paris, France from 10 to 14 September 2001. The American Meteorological Society is a cooperating organization.

Results from field experiments, new developments in theory, and modelling and observational capability that are being undertaken in the context of the World Climate Research Programme (WCRP) Global Energy and Water Cycle Experiment (GEWEX) and other related activities, are expected to be reported. Particular emphasis will be on the linking of disciplines such as coupled atmospheric and land surface models, and cross discipline studies connecting the water and carbon cycle. The advances in scientific knowledge presented will provide new information to assess the impact on water resource management. The scientific themes are: Microphysics of clouds and cloud/aerosol interactions within atmospheric models; The carbon and water cycles and their interaction with the climate system; Hydrology and water resource impacts from catchment to global scales; The global water cycle and its sensitivity to climate change; Remote sensing and land-surface processes.

The conference is Co-Chaired by Prof. Gérard Mégie, Director, Institut Pierre Simon Laplace, and Prof. Soroosh Sorooshian, Chairman, GEWEX Scientific Steering Group, University of Arizona. The deadline for abstracts has passed.

For further information consult the conference web site at http://www.ipsl.jussieu.fr/gewex or contact the Co-Chairs of the organizing committee, Jan Polcher, Institut Pierre Simon Laplace, Laboratoire de Météorologie Dynamique du CNRS, and Paul D. Try, Director, International GEWEX Project Office, via gewex@ipsl.jussieu.fr. (4/01) 
Ninth International Conference on Modelling, Monitoring and Management of Air Pollution, 1214 September 2001, Ancona, Italy

The Ninth International Conference on Modelling, Monitoring and Management of Air Pollution, organized by Wessex Institute of Technology, will beheld 1214 September 2001 in Ancona, Italy. The American Meteorological Society is a cooperating organization.

Air Pollution 2001 is the ninth international conference in the series on the Modelling, Monitoring and Management of Air Pollution. The meeting will emphasize the development of experimental and computational techniques, which can be used as a tool for the solution and understanding of practical air pollution problems, from which it is possible to evaluate proposed emission control techniques and strategies.

The goal of this conference is to bring together researchers and their recent results relating to the study of air contaminants. It is hoped that information from this conference will increase public awareness of air pollution issues and lay the groundwork for further research on the subject.

The deadline for abstracts has passed. Topics to be covered include: Aerosols and Particles; Air Pollution Modelling; Air Quality Management; Process Studies; Chemical Transformation Modelling; Chemistry of Air Pollution; Comparison of Modelling with Experiments; Damage to Historic Monuments; Data Analysis and Observation; Emission Inventories; Fluid Mechanics for Environmental Problems; Global Studies; Health Problems; Indoor Pollution; Monitoring and Laboratory Studies; Pollution Engineering; Pollution Management; Regulatory Bodies; Turbulence Modelling at Small and Mesoscales; Urban Air Pollution; and Urban and Suburban Transport Emissions.

For further information contact the Conference Secretariat, Gabriella Cossutta, Air Pollution 2001, Wessex Institute of Technology, Ashurst Lodge, Ashurst, Southampton, SO40 7AA (tel: 440238029 3223; e-mail: slwalsh@wessex.ac.uk). (12/00)

\section{0th International Symposium on "Transport and Air Pollution," 17-19 September 2001, Boulder, Colorado}

Following nine previous conferences held since 1986 in Avignon, France, and Graz, Austria, this 10th symposium would be held in Boulder, Colorado. The American Meteorological Society is a cooperating organization.

The symposium is aimed at assessing scientific knowledge in the field of air pollution due to emissions from transportation systems. All transport modes will be considered (road, rail, air and sea), as well as the effects of air pollution on the environment (health effects, dispersion, acid rain, greenhouse effect, etc.). The 10th symposium will consider all these aspects, but will focus particular attention on issues relating to transport emissions, atmospheric transport and diffusion, air chemistry, and integrated air quality modeling. All modes of investigation and analysis will be covered: theoretical, empirical, numerical modeling, and chamber and ambient measurements. The National Center for Atmospheric Research (NCAR), the French National Institute for Transport and Safety Research (INRETS), and the Graz Technical University, Austria, jointly organize the symposium.

The deadline for abstracts has passed. For further information contact the General Chairperson, Walt Dabberdt in care of the symposium directorate at the following address: Sandra Petrie, TAP-2001, NCAR, P.O. Box 3000, 1850 Table Mesa Drive, Boulder, CO 80307-3000 or electronically to sjp@ucar.edu. Symposium and abstract information can be found at the symposium Web site: http:// www.ncar.ucar.edu/TAP/TAP2001.html. (r4/01)

\section{4th Australia New Zealand Climate Forum, 18- 21 September 2001, Darwin, Australia}

The 14th Australia-New Zealand Climate Forum will be held for the first time in Darwin, Australia between 18 and 21 September 2001 (at the Darwin Entertainment Centre). The latest research and applications of climate science in Australia and New Zealand will be presented at the conference.

The main focus of the forum will be tropical climate, which includes, apart from monitoring and prediction, the research and impacts of climate on such things as habitat, rainforests, building and construction, trade and weather related natural hazards. The forum will be a good platform to discuss various management, education and partnerships issues with a common theme of weather and climate.

For registration and general information please contact our Web page at http://www.bom.gov.au/announcements/. (1/01)

\section{Fourth International SRNWP Workshop on Nonhydrostatic Modelling, 24-26 September 2001, Bad Orb, Germany}

The Fourth International SRNWP Workshop on Nonhydrostatic Modelling will be held from 24-26 September 2001 in Bad Orb, Germany. The American Meteorological Society is a cooperating organization.

The aim of the workshop is to provide a forum of information concerning all questions related to fine-scale modeling. The special topic of the workshop is "Numerical techniques for non-hydrostatic modeling." The deadline for abstracts is $\mathbf{1}$ July 2001. Authors will be notified of their acceptance by 1 August 2001. For more information contact J. Steppeler, Deutscher Weterdienst, Frankfurter Str. 135, 63067 Offenbach, Germany (e-mail: Juergen.Steppeler@dwd.de).(10/00;r2/01) 
Fifth European Conference on Applications of Meteorology (ECAM 2001) in conjunction with the First Annual Meeting of the European Meteorological Society (EMS), 24-28 September 2001, Budapest, Hungary

The Fifth European Conference on Applications of Meteorology (ECAM 2001) is being held in conjunction with the First Annual Meeting of the European Meteorological Society (EMS) from 24-28 September 2001 in Budapest Hungary. The American Meteorological Society is a cooperating organization.

Born in September 1999, the EMS has become an association of 24 Meteorological Societies and several major organizations from all over Europe. In order to meet its responsibilities and challenges, the EMS will hold its First Annual Meeting in conjunction with ECAM 2001 and focus on a lively exchange of ideas on the Future of Meteorology in Europe. An array of high-caliber lecturers from WMO, European Organizations, National Meteorological and Hydrological Services and private companies will present views on and overviews of the problem. Among the various aspects covered will be the scientific, technical, industrial, economical and social sides of meteorology and their implications.

The conference program will include invited speakers on the following topics: 1) The demands to meteorology: safety of life and property, quality of life, optimization of economic activities, climate change; 2 ) The tools of meteorology: general views of the evolution of systems of observing, communicating, computing, forecasting, dissemination of information and products; and 3) The structures of meteorology: the European Meteorological Organizations, cooperation/coordination of National Meteorological Services, role of all actors public and private, relation between public and private entities, pricing of basic information.

The deadline for abstracts has passed. The deadline for extended abstracts is 1 May 2001. For further information contact: Hungarian Meteorological Service, P.O. Box 38, H-1024 Budapest, Hungary (tel: +361346-4615/4664; fax: + 361 346-4665; e-mail: intrel@met.hu; Web: http:// www.diamond-congress.hu/ecam) $(3 / 01 ; \mathrm{r} 4 / 01)$

\section{International Conference on Mesoscale Meteoro- logy and Typhoon in East Asia, 26-28 September 2001, Taipei, Taiwan}

The International Conference on Mesoscale Meteorology and Typhoon in East Asia, sponsored by the National Science Council, Central Weather Bureau, and National Taiwan Univ., will be held 26-28 September 2001, at the International Conference Hall, Central Weather Bureau, located in downtown Taipei, Taiwan. This meeting is cosponsored by the Meteorological Society of ROC. The American Meteorological Society is a cooperating organization.

Papers on all research topics related to mesoscale meteorology and typhoon are welcomed including papers on:
1) mesoscale dynamics and modeling; 2) mesoscale processes related to heavy rains; 3 ) mesoscale convective systems in the midlatitudes and tropics; 4) topographic effects and mountainous heavy rain processes; and 5) typhoons at landfall. The conference will have a special session on the scientific results related to monsoon convection from the South China Sea Monsoon Experiment (SCSMEX). There will be poster papers and oral presentations. Proceedings will be available during the meeting.

For more information contact, Dave Jorgensen, NOAA/ NSSL, mail code: N/C/MRD, 325 Broadway, Boulder, CO 80305 (tel: 303-497-6246; fax: 303-497-6930; e-mail: davej@ ncar.ucar.edu) or Ben Jong-Dao Jou, 61, Lane 144, Sec. 4, Kee-Long Road, Dept. of Atmos Sciences, National Taiwan Univ., Taipei, Taiwan (tel: 8862-2362-8962; fax: 8862-2363-3642; e-mail: jou@hp735.as.ntu.edu.tw). (1/01)

\section{Regional Haze and Global Radiation Balance- Aerosols, Measurements and Models: Closure, Reconciliation and Evaluation, October 2-5, 2001, Bend, Oregon}

The International Specialty Conference and Professional Development Course will be held at the Inn of the Seventh Mountain near Bend, Oregon. The conference will specifically address: sources, chemical and physical characteristics of aerosols; measurement methodologies; predictive modeling techniques; and air quality management implications. A visibility-related professional development course, designed to provide both a technical foundation and a timely refresher, will be offered on-site prior to the conference (October 1, 2001). For further information, visit the Web site: http://www.awma.org/awma/confs/cfp.htm. (4/01)

\section{Call for Papers}

\section{6th Annual Climate Diagnostics and Prediction Workshop, 22-26 October 2001, La Jolla, California}

The 26th Climate Diagnostics and Prediction Workshop will be held 22-26 October 2001 at the Scripps Institution of Oceanography of La Jolla, California, which is cosponsoring the workshop with the Climate Prediction Center of the National Centers for Environmental Prediction in Camp Springs, Maryland. The American Meteorological Society is a cooperating organization.

The workshop will provide an opportunity to exchange information, ideas and opinions on many topies, including: Review of the 2000-2001 climate; Assessment of climate predictions in 2000-2001; Precipitation forecasting in complicated terrain; Drought/water monitoring in the West Monsoons; Diagnosis and prediction of intraseasonal oscillations; Diagnosis and prediction of decadal variations; Global, regional and local ocean-land-atmosphere interactions

Presentations will be in both poster and oral form. Poster presentations are encouraged, since time constraints 
and a large number of papers necessarily limit the number of oral presentations we can accommodate. Please use email to send your abstracts to cdwshop@ncep.noaa.gov. Include: Title, author(s), affiliation(s), a brief abstract, email address, phone number, facsimile number, poster/oral preference. The above information is due by $\mathbf{2}$ July 2001. (3/01)

\section{Call for Papers}

\section{International Workshop on Operational Marine Forecasting, 18-22 November 2001, Halifax, Nova Scotia, Canada}

A workshop on Operational Marine Forecasting will be held from the 18-22 of November 2001, in Halifax, Nova Scotia, Canada. A preliminary program, registration, hotel and general information will be posted on the Atlantic Environment Canada Greenland Web site (http:// atl.ec.gc.ca) by March of 2001.

The workshop will consist of oral and poster presentations and hands-on labs. Topics should be related to marine forecasting, and can also cover areas surrounding and supporting that activity, such as sources of, and working with marine data.

Papers and posters are solicited in the following areas: measuring the wind over marine areas, (including: remote sensing, instrumentation, rectification of reports); forecasting wind (including transitioning hurricane effects, coastal and lake winds); forecasting in data-void and data-sparse areas; marine wind models; marine data; fog forecasting; wave forecasting (including: trapped fetch, seiche, storm surges, wave models); ice movement; and vessel icing.

Deadline for abstracts is 30 May 2001. Abstracts are to be submitted electronically to peter.bowyer.ec.gc.ca. For information contact Peter Bowyer, Environment Canada, 16th floor, 45 Alderney Drive, Dartmouth, NS, B2Y 2N6, Canada (Tel: 902-426-9181; fax: 902-426-4873; e-mail: peter.bowyer.ec.gc.ca. (12/00; r2/01)

\section{Third International Symposium on Environmental Hydraulics with a Special Theme in Urban Fluid Dynamics, 5-8 December 2001, Tempe, Arizona}

This is to invite you to attend the Third International Symposium on Environmental Hydraulics with a special Theme in Urban Fluid Dynamics (ISEH 2001) to be held in Tempe, Arizona, 5-8 December 2001. Tempe is in the greater Phoenix metropolitan area, known as the "Valley of the Sun." The overall theme of the symposium is the application of basic research to address issues facing policy makers in the management of air and water re-sources. In addition to traditional environmental hydraulics topics, there will be sessions on the general theme of urban fluid mechanics, including water quality and atmospheric issues.

A keynote speaker will address the general topic of worldwide urban air and water problems. Several invited speakers will review the present state of knowledge in critical topic areas, and contributed papers will be presented in oral or poster sessions. Session topics to be covered during this symposium include environmental hydraulics and urban fluid dynamics. Several post-symposium trips to locations such as the Grand Canyon, Las Vegas, Hoover Dam, Sedona, the Navajo Indian Reservation, and Monument Valley will be available.

The deadline for submission of abstracts has passed. Authors should be notified of their acceptance by 15 March 2001. All papers will be published in the symposium proceedings on CD-ROM, with an accompanying abstract book. Camera-ready manuscripts are due 1 June 2001.

The ISEH $2001 \mathrm{Web}$ site at www.eas.asu.edu/iseh2001 will be used to convey the most current symposium information. Please refer to this site regularly. For additional information, contact the Chairperson, Don Boyer, MAE/ EFD, P.O. Box 876106, Tempe, AZ 85287 (tel: 480-9651382; fax: 480-965-1384; e-mail: don.boyer@asu.edu). $(8 / 00 ; r 4 / 01)$

The World Weather Research Programme's (WWRP) International Conference on Quantitative Precipitation Forecasting (QPF) 2-6 September 2002, University of Reading, Reading, Berks., United Kingdom

WMO's World Weather Research Programme (WWRP) and the Royal Meteorological Society are cosponsoring the International Conference on Quantitative Precipitation Forecasting. The conference is being hosted by the University of Reading, Reading, Berks., United Kingdom, from 2-6 September 2002. The American Meteorological Society is a cooperating organization.

The conference will cover a wide range of issues relating to QPF, from the measurement and forecasting of precipitation through to the application and benefits of quantitative information of precipitation fields and will conclude by identifying gaps in current knowledge with key future areas of work. Abstract submissions are welcome under the topic headings of 1) Socioeconomic impacts and environmental stresses of precipitation events; 2) Precipitation measurement, estimation and associated issues from observing systems; 3) Nowcasting, including deterministic, conceptual and probabilistic methods; 4) NWP-based forecasting methods, including precipitation assimilation, resolution issues, post processing and ensemble methodologies; 5) Prediction techniques and predictability of extended range and seasonal forecasting; and 6) Applications of QPF and demonstration of potential benefits to a range user communities.

The deadline for submission of abstracts has passed. Further information and details can be obtained from http://www.royal-met-soc.org.uk/ or through contacting execsec@royal-met-soc.org.uk. (2/01; r4/01) 